\title{
Adaptive glass panels using shape-memory alloys
}

\author{
Filipe Amarante dos Santos • Chiara Bedon • \\ Mariana Sacadura
}

Received: 20 December 2015 / Accepted: 19 March 2016 / Published online: 19 April 2016

(C) Springer International Publishing Switzerland 2016

\begin{abstract}
Due to the growing application of laminated glass panels in building facades and roofs, tending towards the minimization of frameworks, substructures and supports, technological solutions based on the use of glass panels with increasingly wide dimensions and modern design principles are becoming more frequent. The growing use of structural glass applications is leading to "lighter" and "smarter" optimized design solutions. The design of such applications greatly depends on the material mechanical properties of their structural elements and on their sensitivity to ambient and loading conditions. This is the specific case of laminated glass, where a temperature and time loading sensitive interlayer is generally used to bond together two (or more) glass panes with brittle behavior and rather limited tensile resistance. In this research paper, a novel adaptive glass panel concept is developed by using shape-memory alloy (SMA) cables, and assessed by means of Finite-element numerical studies and experimental validation. Based on the case study of an existing laminated glass roof panel, several geometrical configurations of practical interest are investigated. A key role in the proposed approach is the
\end{abstract}

F. A. dos Santos - M. Sacadura

CEris, ICIST, Faculdade de Ciências e Tecnologia,

Universidade NOVA de Lisboa, Quinta da Torre, 2829-516

Caparica, Portugal

e-mail: fpas@fct.unl.pt

C. Bedon $(\varangle)$

DIA, University of Trieste, Trieste, Italy

e-mail: bedon@dicar.units.it application of external pre-stressing based on the Joule heating of the SMA bracing system. The structural efficiency of the cable system is emphasized by taking into account the effects of ordinary wind pressures and temperature variations. Due to the innovative adaptive control system, as shown, the structural performance of traditional laminated glass panels can be enhanced, e.g. optimized in terms of maximum displacements and stresses in the glass, as well as in the overall dimensions and thicknesses of the glass panes.

Keywords Laminated glass - Shape-memory alloys · Adaptive control · Finite-element numerical modeling . Experimental prototype

\section{Introduction}

In modern architecture, the use of glass panels in building facades and roofs is continuously increasing, due to a multitude of aspects. The rising demand of transparency, in particular, leads designers towards the minimization of bracing systems and frameworks, with preference for frameless structural glass applications and adhesive connections or metal point fixings only (Bedon and Amadio 2016; Blyberg et al. 2012; Bos and Veer 2007; Dispersyn et al. 2015; Overend et al. 2013; Petterson 2011; Batinger and Feldmann 2010). The generalized trend of structural optimization also fosters the ongoing development of 'ultra-light' structural components in buildings and a continuous chal- 


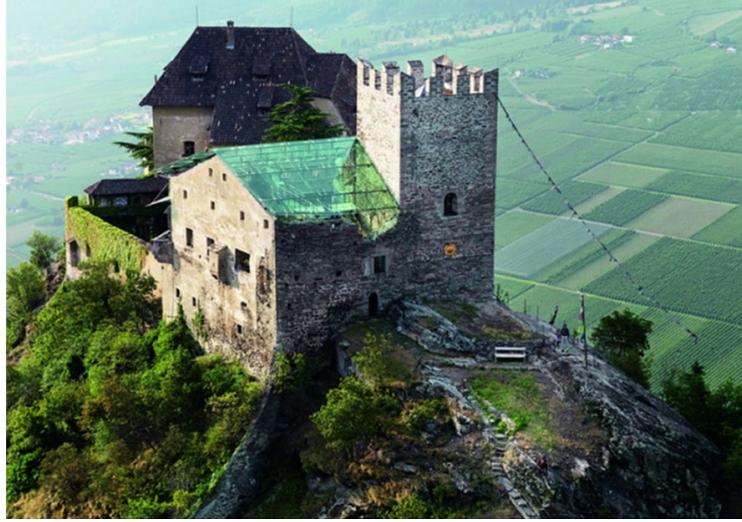

Fig. 1 Messner Mountain Museum Firmian @ Georg Tappeiner

lenge for designers and research scientists (e.g. Shitanoki and Bennison 2014). A balance between this structural optimization processes, e.g. associated with the continuous innovation in architectural concepts and aesthetic demands, and safe design requirements has to be always guaranteed.

Point-supported glass panels, for example, are frequently used in glass walls and roofs, as in Messner Mountain Museum Firmian, see Fig. 1. In these kind of applications, the typical glass panel often consists of a laminated glass (LG) element, e.g. a layered crosssection obtained by assembling two or more glass plies and thermoplastic interlayers. The external loads (e.g. dead load and service loads) are then usually transferred from the glass panel itself to the structural background by means of metal connectors (e.g. special fasteners, bolted joints, etc.), typically positioned near the corners and at mid-span of the longest edges.

In order to satisfy the design requirements of current standards for the design of structural glass components, both the maximum deflections (e.g. at the center of the panel) and the maximum tensile stresses in glass (e.g. at the center of the panel and near the pointsupports) should be properly limited. From a mechanical point of view, the main influencing parameters of structural glass are typically represented by its basic components, e.g. glass and the bonding interlayers. While glass is a typical tensile brittle material, with limited tensile strength but elastic properties relatively stable over normal temperature ranges (EN 572-2: 2004), the key elastic parameters of common interlayers for structural glass applications can vary significantly with ambient and loading conditions. Both the shear modu- lus $\left(G_{i n t}\right)$ and the modulus of elasticity $\left(E_{i n t}\right)$ of these interlayers, in fact, are strongly sensitive to temperature variations and time loading, with generally strong decrease of their nominal values with temperature and time loading increases. This is especially true for PVB films, being representative of the original and 'conventional' laminated glass solution for several decades (Meyers 1986), but typically characterized by intrinsic limitations and largest degradation of the reference elastic moduli (Bennison et al. 2008; Van Duser et al. 1999), compared to other interlayer typologies (Callewaert et al. 2012).

Often, especially in these last years, the improvement of both the pre-cracked and post-failure structural performances of structural glass assemblies has been proposed in the form of hybrid and composite technological solutions, namely derived by the interaction between traditional structural glass elements and steel reinforcements and tendons (Martens et al. 2015; Bedon and Louter 2014), GFRP layers (Martens et al. 2015; Neto et al. 2015) or external steel cables (Cupac and Louter 2015; Jordão et al. 2014; Louter et al. 2014; Kamerling 2012).

In this paper, as an exploratory investigation towards prototyping, an advanced, adaptive control approach is applied to traditional point-supported laminated glass panels, to mitigate the hazardous effects of combined loading conditions and ambient temperature variations on the performance of the so assembled structural components. The proposed 'smart panel' consists of the LG panel itself and a complementary bracing system of external cables obtained from shape-memory alloys (SMAs) actuators. The proposed adaptive control approach was inspired in a previous work (see Santos et al. 2014) which addressed the control of a suspended glass façade under wind actions, while a further application was also presented in Santos et al. (2016) for cable-supported facades under blast events.

In the implementation and calibration of the proposed design concept, careful consideration is paid for the degradation of the mechanical properties of the thermoplastic interlayers, which is potentiated by the fact that large point-supported LG panels are usually used in building facades and roofs, and thus are often subjected to high temperature variations during the day.

The main objectives of the current exploratory research project are achieved based on sequential steps ((i)-(iii)). As a preliminary stage of the investigation, (i) an optimization study aimed to emphasize the influ- 
ence of the geometrical configuration of the cable bracing system on the overall structural response of pointsupported LG panels is first performed. This parametric study is carried out by means of preliminary finiteelement (FE) models, in the form of static simulations performed with the SAP2000 computer software (Computers \& Structures Inc 2015), by considering a wide set of geometrical configurations of practical interest and a service uniform pressure representative of a conventional wind load. The aim is to maximize the beneficial structural effect of SMAs on the full smart assembly, e.g. in terms of maximum deformations and stresses in the LG panel, as well as to minimize the aesthetic impact of the same SMA cables. A set of pseudodynamic FE numerical simulations is then carried out (ii) on an adaptive smart panel subjected to wind loads, by using a proportional-integral-derivative (PID) control approach. The major advantage of the PID control approach is that it enables the SMA cables to control the structural deformation in glass deriving from the applied external loads, based on a pre-fixed maximum deformation limit. At this stage, a selected geometrical configuration only is taken into account for the bracing system, based on the outcomes of step (i). Finally, (iii) an experimental prototype is also presented and investigated, in order to further explore the novel design concept. As shown, due to the active contribution of the proposed SMAs cables and the PID adaptive control system, the maximum deflections in the examined point-supported LG panels can be markedly reduced, compared to traditionally point-supported assemblies. The major effect of this finding can be exploited in an optimization of the glass panel itself and in the possibility of 'ultra-thin', 'large-span' glass envelopes. The main advantage of the explored active LG panels is in fact that as far as the deformations due to the external loads are minimized, the amount of maximum principal stresses in the glass is not compromised.

In this paper, the main outcomes deriving from steps (i)-(iii) are critically discussed, in order to derive some general rules of practical use towards a prototyping and full optimization of this novel design concept. It is in fact expected, although further extended investigations and validations are still required, that the same design concept could be also extended to general 'smart' glass applications.

\section{Structural analysis of large LG panels}

From a practical point of view, the structural use of glass is not necessarily more complex than other traditional materials, but requires specific issues primarily related to its intrinsic brittleness and limited tensile resistance (EN 572-2: 2004). To overcome its typical brittle behavior, laminated glass was designed by bonding together two or more panes of glass with intermediate polymer interlayers, e.g. PVB foils in the majority of the cases (Bennison et al. 2008; Van Duser et al. 1999). The so obtained resisting cross-section, represented for several decades the 'reference' structural glass section for application under ordinary loads as well as impacts and exceptional events (Meyers 1986). The typical interlayer-independently on its typologygenerally consists in a plastic component interposed within the LG assembly, in order to obtain a thick and stiffer/stronger composite section as well as to improve its post-breakage behavior, keeping the glass fragments together (e.g. in case of glass failure) and avoiding an instantaneous collapse. The interlayers material properties, however, are time, temperature and time loading dependent, hence they strongly affect the global structural performance of the full laminated glass assemblies they belong to. Therefore, this issue should be deeply investigated in order to fully understand and predict LG behavior along time.

Since the response of the polymer is non-linear viscoelastic and depends on several aspects, the resulting state of stresses and deformations is rather difficult to exactly predict and often requires sophisticated full three dimensional, accurate but time consuming viscoelastic FE numerical analyses. This finding is especially true in the case of specific loading and boundary conditions which cannot be associated to idealized restraints of classical literature (see for example in Bedon and Amadio 2016). Nevertheless, several simplified analytical methods and approaches available in literature can be used in the design practice, in order to obtain rather accurate predictions. This is the case for example of the enhanced effective thickness (EET) method (Galuppi and Royer-Carfagni 2012), that in the current research project has been taken into account for the examined case study, as discussed in the following sections. 
Fig. 2 Roof modular unit of the Reinhold Messner Castle (Model 'S0'), nominal dimensions in millimeters

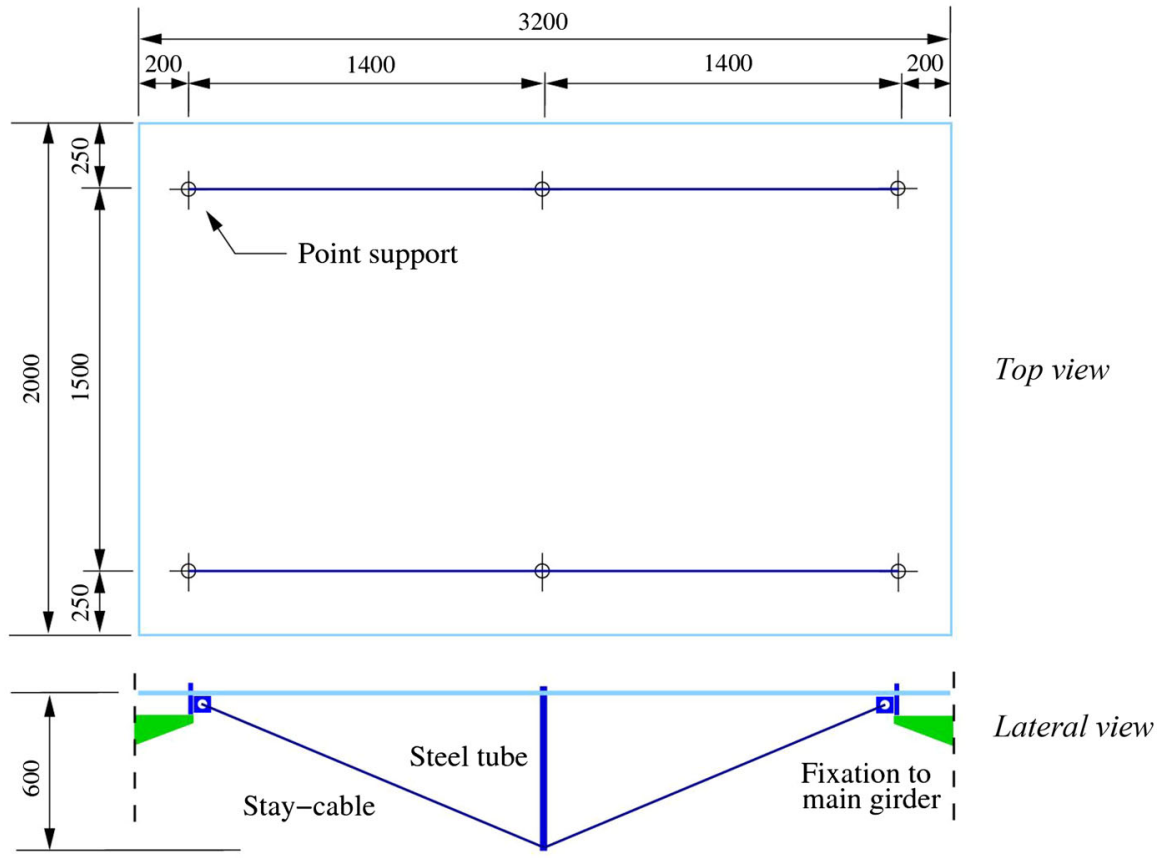

\section{Application of existing analytical methods to a LG case study}

The LG panel which inspired this exploratory research project is based on a structural solution which was used during the reconstruction of the roof (with a total surface of $\sim 200 \mathrm{~m}^{2}$ ) in the Reinhold Messner Castle, Italy, see Fig. 2. The rectangular LG modular unit is $3200 \mathrm{~mm}$ long $\times 2000 \mathrm{~mm}$ wide, and is built up of two glass sheets of 8 and $10 \mathrm{~mm}$ nominal thicknesses, with a $1.52 \mathrm{~mm}$ thick middle PVB interlayer acting as bonding film between them. Due to the large size of the typical LG unit, a bracing solution consisting of two lateral restraining cables arranged in a triangular configuration was used (Froli and Lani 2007). Each cable was then provided with a $600 \mathrm{~mm}$ long steel strut connected at the mid-span to the longest edges of each LG pane and acting as a mid-span deviator. As a pointsupported LG roof element, the typical modular unit is subjected to daily variations of temperature and wind pressures.

In order to preliminary assess the structural response of the given nominal geometry under service wind loads only, some analytical calculations were preliminary carried out before the execution of sophisticated FE simulations, based on simple but accurate analytical methods available in literature. The Enhanced Effec- tive Thickness method (Galuppi and Royer-Carfagni 2012), for example, represents a useful and practical tool implemented from the original Wölfel approach for sandwich beams only (Wölfel 1987), and further extended to a multitude of boundary and loading distribution configurations of practical interest for construction systems. In this specific case, the EET method was taken into account, so that the FE studies discussed in this paper could be based on computationally efficient, equivalent shell models, rather than full 3D solid models (see Sects. 4 and 7).

The main output of the EET approach are in fact an effective thickness value for the calculation of displacements and one for the stresses analysis. In doing so, the thickness of the glass panes and the interlayer, as well as the two material properties, must be taken into account. In the case of the interlayer foils, due to their viscoelastic nature and time/temperature dependency, an equivalent shear modulus $G_{\text {int }}$ associated to welldefined loading conditions is conventionally assumed for approximate calculations. As a result, based on master curves available in literature for common interlayers, see for example (Van Duser et al. 1999; Callewaert et al. 2012), simplified analytical estimation can be rationally performed for a wide set of configurations. The correctness of the obtained results strictly depends on the accurate calibration of the interlayer shear modu- 
Table 1 Effective thicknesses for the estimation of maximum displacements and stresses in distinct loading configurations, as calculated by means of Eqs. (1)-(4)

\begin{tabular}{|c|c|c|c|c|c|c|}
\hline \multirow[t]{2}{*}{$G_{\text {int }}(\mathrm{MPa})$} & \multicolumn{2}{|c|}{ Loading condition } & \multicolumn{4}{|c|}{ EET method } \\
\hline & $T\left({ }^{\circ} \mathrm{C}\right)$ & Time & $\eta$ & $h_{w}(\mathrm{~mm})$ & $h_{1 ; \sigma}(\mathrm{mm})$ & $h_{2 ; \sigma}(\mathrm{mm})$ \\
\hline 500 & - & Impact load & 0.9998 & 19.49 & 19.40 & 19.52 \\
\hline 8.06 & 20 & $3 \mathrm{~s}$ & 0.9875 & 19.19 & 19.29 & 19.39 \\
\hline 0.052 & 50 & 50 years & 0.3381 & 12.74 & 15.08 & 13.79 \\
\hline
\end{tabular}

lus, as well as on the basic assumptions of the analytical models themselves.

In order to apply the EET method for the case study object of investigation (e.g. a point-supported, three-layer LG panel under uniformly distributed wind pressure), the $\Psi$ coefficient was first calculated (see "Annex"), being this latter parameter dependent on the boundary conditions, load distribution and panel aspect ratio $\lambda$ (Galuppi and Royer-Carfagni 2012). For the specific purpose of this research contribution, the $\psi$ coefficient corresponding to LG panels with 4 pointsupports at the corners and uniformly distributed loads was taken into account, as an interpolated value derived from Table 2 (with $\lambda=0.625$ ). A more detailed EET application to the object of study, in this context, would in fact require the separate analytical calculation of the aforementioned $\psi$ coefficient for each one of the SMA reinforced panel geometries under investigation (e.g. due to the presence of intermediate supports due to the steel deviators, see Fig. 3). In this hypothesis, once the $\Psi$ coefficient is estimated and the nominal geometry of the layered cross-section is known, the $\eta$ parameter is in fact given by:

$0 \leq \eta=\frac{1}{1+\frac{h_{\text {int }} E}{G_{\text {int }}\left(1-\nu^{2}\right)} \cdot \frac{D_{a b s}}{D_{\text {full }}} \cdot \frac{h_{1} h_{2}}{h_{1}+h_{2}} \cdot \psi} \leq 1$

where $h_{\text {int }}, h_{1}, h_{2}$ are the thicknesses of the interlayer and of the glass panes 1 and $2, E=70 \mathrm{GPa}$ is the nominal Young's modulus of glass (EN 572-2: 2004), $G_{\text {int }}=f(t, T)$ is the shear modulus of the interlayer, $v$ the Poisson's ratio. $D_{a b s}$ and $D_{f u l l}$, finally, represent the bending stiffnesses of the composite resisting section associated to the well-known limit configurations, e.g. the 'layered' (e.g. $G_{i n t} \rightarrow 0$ ) and 'monolithic' (e.g. $G_{\text {int }} \rightarrow G$ ) limits. In this sense, the $\eta$ parameter directly reflects the interlayer capacity to transfer shear loads between the bonded glass panes, corresponding to 0 when the interlayer has null shear stiffness (layered behavior) and to 1 when the interlayer provides a fully rigid shear connection between the glass panes (monolithic).

Based on Galuppi and Royer-Carfagni (2012), the effective thickness for the estimation of the expected displacements was calculated as:

$h_{w}=\sqrt[3]{\frac{1}{\frac{\eta}{h_{1}^{3}+h_{2}^{3}+12 I_{s}}+\frac{1-\eta}{h_{1}^{3}+h_{2}^{3}}}}$,

with $I_{S}$ the effective bending stiffnes (see Galuppi and Royer-Carfagni (2012) for details).

In terms of stresses, otherwise, the effective thickness was calculated by means of Eqs. (3) and (4):

$h_{1 ; \sigma}=\sqrt{\frac{1}{\frac{2 \eta d_{1}}{h_{1}^{3}+h_{2}^{3}+12 I_{s}}+\frac{h_{1}}{h_{w}^{3}}}}$,
$h_{2 ; \sigma}=\sqrt{\frac{1}{\frac{2 \eta d_{2}}{h_{1}^{3}+h_{2}^{3}+12 I_{s}}+\frac{h_{2}}{h_{w}^{3}}}}$,

where the distances $d_{1}$ and $d_{2}$ are defined in the "Annex".

In order to investigate the given LG panel geometry under several loading configurations of practical interest, ideally comprised between the aforementioned layered and monolithic behaviors, the following shear moduli were taken into account (Bennison et al. 2008; Van Duser et al. 1999):

- $G_{i n t}=500 \mathrm{MPa}$, equivalent quasi-static, instantaneous/impact load ('Glassy' modulus of PVB, corresponding to a monolithic behavior, in the hypothesis that Hertzian fracture effects are fully neglected);

- $G_{i n t}=8.06 \mathrm{MPa}, T=20^{\circ} \mathrm{C}$ and $t=3 \mathrm{~s}$ (short-term wind pressure, calculated in accor- 
dance with the specifications provided in (CNR DT210/2013));

- $G_{\text {int }}=0.052 \mathrm{MPa}, \mathrm{T}=50^{\circ} \mathrm{C}$ and $t=50$ years (layered behavior).

The corresponding effective thicknesses, according to Eqs. (2)-(4), are collected in Table 1, and used as key input parameters for the FE parametric studies proposed in Sect. 4.

\section{Static optimization of the LG panel}

Based on the reference data collected in Sect. 2 and Fig. 2, a parametric FE investigation was carried out to provide an appropriate, exploratory insight on the influence of the cable configuration on the global structural response of the examined LG panel. In this sense, this first FE study was performed by fully neglecting the active contribution of the smart SMA actuators, but for static optimization purposes only. In order to accomplish this goal, a series of FE models were developed using the SAP2000 computer software (Computers \& Structures Inc 2015).

Based on the EET method, the typical LG pane was modeled in the form of four-node quadrilateral shell elements with six degrees of freedom per node and nominal thickness derived from Table 1. At the same time, the struts were modeled using rigid 3D frame elements, while the bracing cables were described by means of geometrically nonlinear cable elements available in the SAP2000 library (with $6 \mathrm{~mm}$ their nominal diameter). Through the parametric study, the so assembled FE models were derived from the initial 'reference' case study model depicted in Fig. 2 (model 'SO', in the following), by replacing the central strut with two struts of total length equal to $600 \mathrm{~mm}$. Six geometrical configurations were considered during the full parametric study. In them, the distance $d$ between the struts was modified in the range comprised between 400 and $2400 \mathrm{~mm}$. The so assembled FE configurations are listed in Fig. 3. In terms of mechanical characterization of materials, both glass and the cables were described in the form of linear elastic materials, with nominal mechanical properties for both of them. In the case of the SMA cables, in particular, the E-modulus was set equal to $40 \mathrm{GPa}$, based on the mechanical calibration obtained from experimental tests on small specimens.

The original model S0 and its S1 to S6 variations were subjected to a uniformly distributed pressure of
$1 \mathrm{kN} / \mathrm{m}^{2}$, to simulate a reasonable wind pressure (with $\mathrm{T}=20^{\circ} \mathrm{C}$ and $t=3 \mathrm{~s}$ the corresponding conventional temperature/time-loading parameters). At this stage, geometrically nonlinear, static simulations only were carried out.

The obtained responses are shown in Fig. 4 for all the six configurations of Fig. 3, in terms of qualitative distribution of maximum out-of-plane displacements and maximum principal stresses in the glass $\left(\sigma_{11}\right.$ and $\left.\sigma_{22}\right)$.

As shown in Fig. 4a, in particular, it can be seen that the maximum displacements in glass are rather sensitive to the geometrical configuration of the cable restraining system, being this latter an input parameter of paramount importance for the purpose of this research investigation. It can be also clearly seen that the performance of the original system S0 can suffer significant modifications, e.g. in terms of deformed shape, amount of maximum deformations and consequently distribution of principal stresses in the glass (see Fig. 4b, c), by choosing an alternative configuration for the bracing cables.

In order to better quantify the effects deriving from the cables geometry, in Fig. 5a-c the correlation of out-of-plane displacements and maximum principal stresses in the glass is also proposed, as obtained from a direct comparison between the response of the original S0 system and the tested S1-S6 configurations, by taking into account three control points. These key points are positioned at the mid-span section of the long edge (point A), at the mid-span section of the short edge (point B) and at the center of the LG panel (point $\mathrm{C}$ ), respectively. The results are collected in non-dimensional form, e.g. in the form of deformation $\left(u_{i} / u_{0}\right)$ and stress $\left(\sigma_{i} / \sigma_{0}\right)$ ratios, for each $i$ case $(i=1, \ldots 6)$, as compared to the $\mathrm{S} 0$ reference model.

The advantage of this type of comparative study is that the optimal solution can be immediately emphasized, within the explored shape configurations. In the case of the S2 option, in particular, a decrease up to $30 \%$ in terms of displacements at the center of the pane (point $\mathrm{C}$ ) and up to $50 \%$ along the longest LG edge (point A) can be obtained, see Fig. 5a. The maximum displacements achieved along the short edge (point B), conversely, are not greatly influenced by the shape of the restraining system. In terms of maximum principal stresses in glass (see Fig. 5b, c), by adopting the same $\mathrm{S} 2$ configuration, it is also possible to obtain a further performance improvement for the examined system, 
Fig. 3 Geometrical configurations of the tested $\mathrm{S}_{i}$ models (lateral view): $d_{1}=400 \mathrm{~mm}, d_{2}=$ $800 \mathrm{~mm}, d_{3}=$ $1200 \mathrm{~mm}, d_{4}=$ $1600 \mathrm{~mm}, d_{5}=$ $2000 \mathrm{~mm}, d_{6}=2400 \mathrm{~mm}$

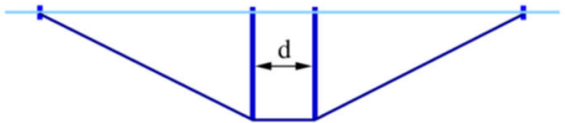

S1

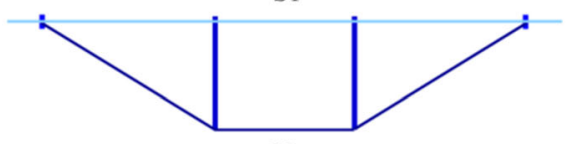

S2

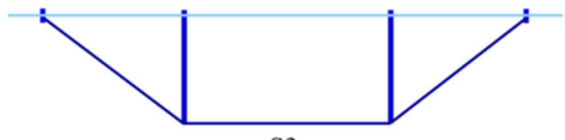

S3

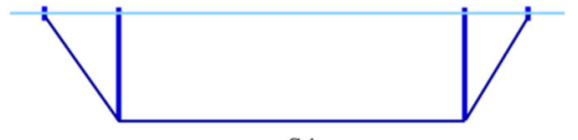

S4

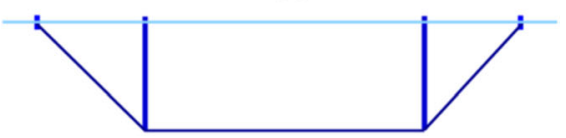

S5

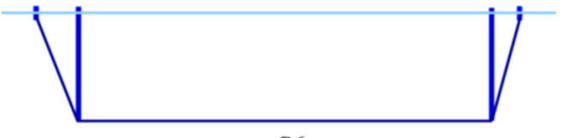

with consistent stress variations for all the A, B, C control points.

As a result, the $\mathrm{S} 2$ solution was further taken into account-as 'optimized' geometrical configurationfor the assessment and exploration of SMAs effects, see Sect. 5.

\section{Adaptive exterior pre-stressing for LG panels}

Exterior pre-stressing is an innovative technique that allows to efficiently control deformations and stresses in large LG panes or beams (see Jordão et al. (2014), for example), due to the high eccentricity of the cables. In accordance with this design concept, the cables are typically anchored to the structural glass assembly and arranged in a polygonal layout. The same cables are then deviated by struts that work under compression and introduce an upward deviation force in the pane. By pre-stressing the cables, specifically, it is in fact possible to partially compensate for the self-weight of both the structural and nonstructural elements, leading to lighter solutions. At the same time, the initial prestress induces in glass an initial state of stresses able to provide, through the overall structural performance of the reinforced system, a certain level of pre-cracked initial stiffness and post-cracked ductility/residual resistance.

The structural response of a pre-stressed LG pane can be typically associated with two main components, e.g. (i) an axial response of the cables/glass panels/struts assembly and (ii) a flexural response of the glass panel itself. Certainly, an optimized combination of the (i) axial and (ii) flexural terms is mandatory, but this goal can be rationally achieved at a pre-design stage, leading to a multitude of possible and very dif- ferent overall responses. The optimal solution, which typically allows to significantly decreasing the thickness of the panel, is represented by the minimization of possible flexural phenomena in glass, and this condition can be rationally achieved by emphasizing the axial contribution of the cables on the overall structural response of the assembled system.

Compared to 'traditional' pre-stressing solutions, the major advantage of the adaptive control system proposed in this paper is represented by the capacity to compensate, in real time, the displacements induced by external loads (e.g. a uniform pressure representative of wind loads acting on the roof LG panels, in this specific case), by continuously adjusting the level of tensile stresses in the bracing system. This goal is achieved thanks to the actuators chosen for this purpose, e.g. the SMA wires, through temperature modulation by Joule effect. SMAs are a new generation of silent actuators, with no moving parts, in which the activation is derived from the material itself due to the so-called 'shape-memory effect' (SME), see for example (Cismasiu and Santos 2008; Santos et al. 2015). The SME allows the material to recover its original shape through a thermal cycle, after withstanding large deformations. During this cycle, the material is able to exert a strong force, as it attempts to regain its original shape. NiTi actuators, based on the SME, present outstanding performance in actuation stress and reliability (Huang 2002), with a high corrosion resistance (Duerig and Pelton 1994). Although activation times can be almost instantaneous when heating the SMA elements, the cooling process is mostly controlled by heat convection between the SMA elements and the surrounding air. This means that the cooling process usually compromises the full dynamic performance of active control systems in large civil engineering struc- 


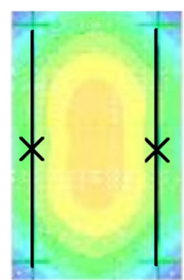

S0

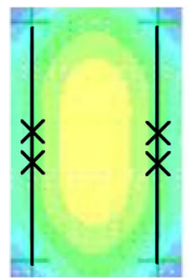

S1

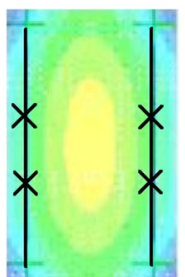

S2

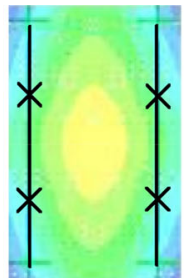

S3

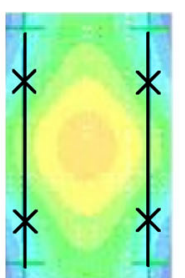

S4

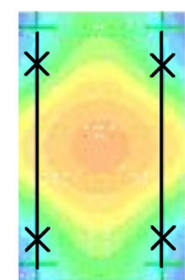

S5

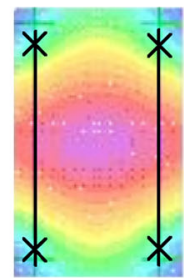

S6

$-6.6-6.0-5.4-4.8-4.2-3.6-3.0-2.4-1.8-1.2-0.6 \quad 0.0 \quad 0.6 \quad 1.2$

(a)

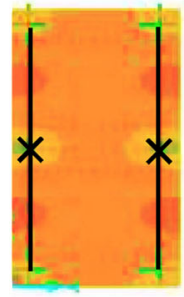

So

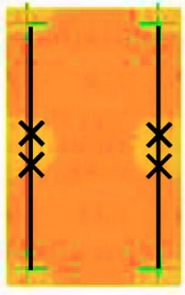

$\mathrm{S} 1$

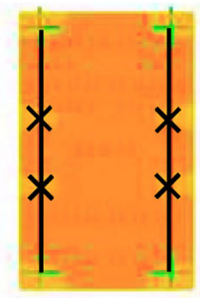

S2

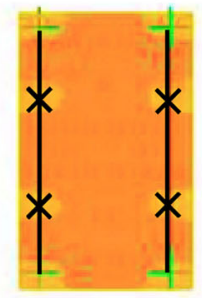

S3

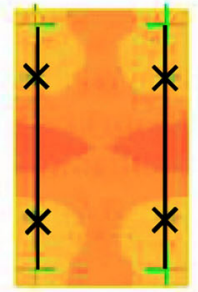

S4

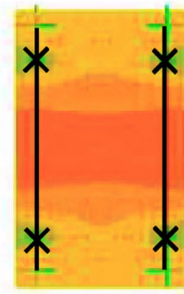

S5

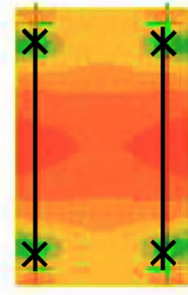

S6

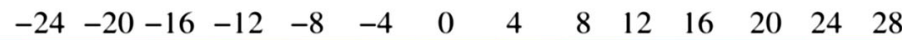

(b)

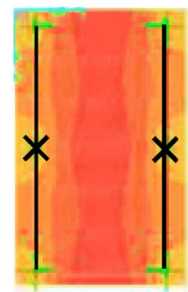

S0

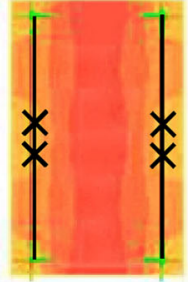

S1

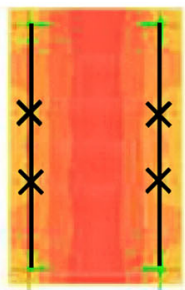

S2

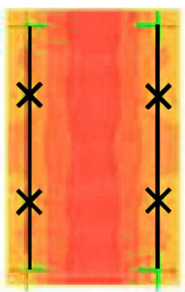

S3

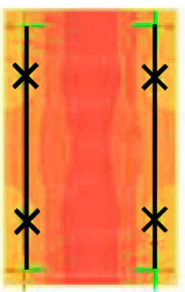

S4

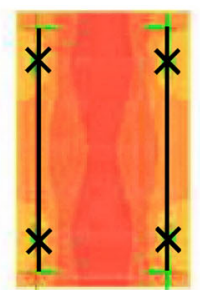

S5

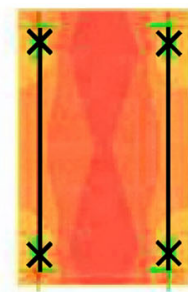

S6

$\begin{array}{llllllllllllll}-12 & -10 & -8 & -6 & -4 & -2 & 0 & 2 & 4 & 6 & 8 & 10 & 12 & 14\end{array}$

(c)

Fig. 4 Static response of the SO-S6 LG panels under a reference wind pressure of $1 \mathrm{kN} / \mathrm{m}^{2}\left(T=20^{\circ} \mathrm{C}\right.$ and $t=3 \mathrm{~s}$, with $\left.G_{i n t}=8.06 \mathrm{MPa}\right)$. a Out-of-plane displacements (mm), b maxi-

mum principal stresses in glass, $\sigma_{11}(\mathrm{MPa})$, c maximum principal stresses in glass, $\sigma_{22}(\mathrm{MPa}), \mathrm{SAP} 2000$

The controller transfer function $G_{c}(s)$ comprehends three terms, each one associated with the corresponding control action, yielding to:

$G_{c}(s)=K_{p}\left(1+\frac{1}{T_{i} s+T_{d} s}\right)$, idealized and optimized to cope with mean wind speed daily variations, rather than fast wind fluctuations associated to turbulence. The control strategy for the adaptive pane was based on a PID controller, e.g. combining the proportional, integral and derivative control actions. where $K_{p}$ is the proportional gain, $T_{i}=K_{p} / K_{i}$ is the integral time and $T_{d}=K_{d} / K_{p}$ is the derivative 


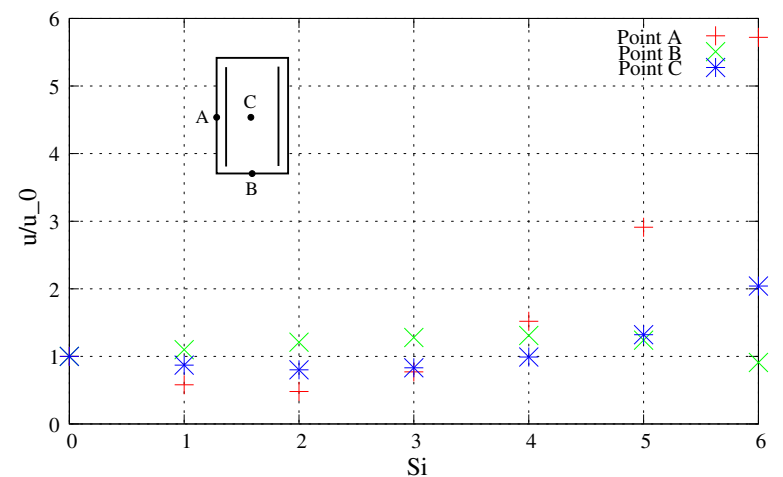

(a)

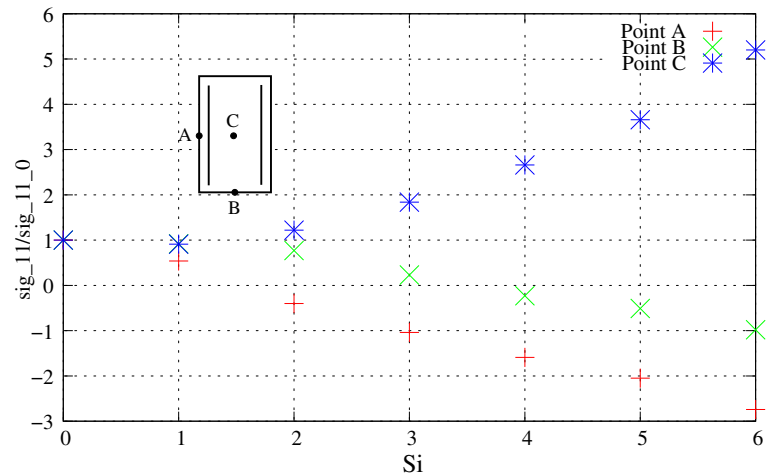

(b)

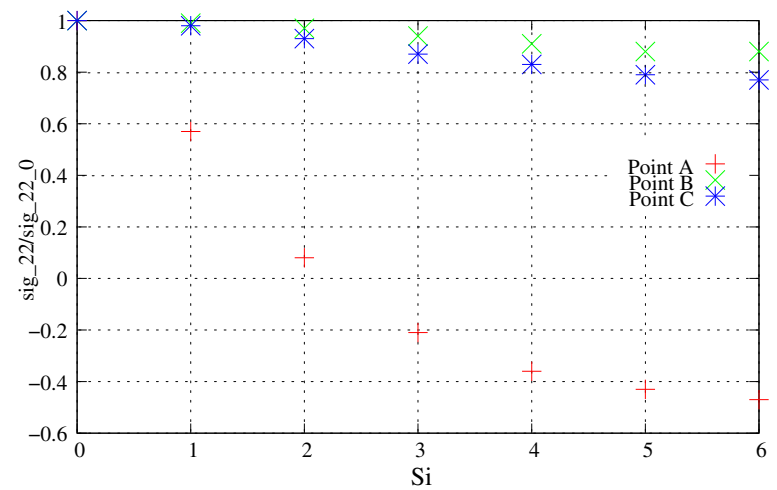

(c)

Fig. 5 Static response of the SO-S6 LG panels under a reference wind pressure of $1 \mathrm{kN} / \mathrm{m}^{2}\left(T=20^{\circ} \mathrm{C}\right.$ and $t=3 \mathrm{~s}$, with $\left.G_{i n t}=8.06 \mathrm{MPa}\right)$. a Out-of-plane displacements $\left(u_{i} / u_{0}\right)$; b maximum principal stresses in glass $\left(\sigma_{11, i} / \sigma_{11,0}\right)$; c maximum principal stresses in glass $\left(\sigma_{22, i} / \sigma_{22,0}\right)$, as a function of the reference "Si" geometrical configuration $(i=0, \ldots, 6)$, SAP2000

\section{(Position PID controller)}

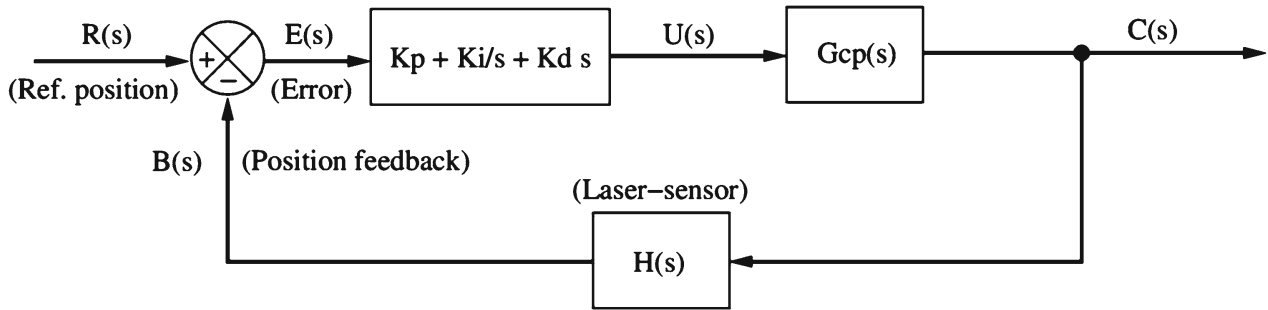

Fig. 6 Block diagram of the PID control system

time. Being a closed-loop control system, the position output signal $C(s)$ is fed back to the summing point, where it is compared with the reference position input $R(s)$, yielding the actuating error signal $E(s)$. The output signal of the controller is $U(s)$ and the feedbackpath transfer function is $H(s)$ which evaluates the out- put variable in order to make it comparable with the reference input signal, resulting in the feedback position signal, $B(s)$. Figure 6 shows the block diagram of the position control system for the glass pane. The full controlled process is defined by the transfer function $G_{c p}(s)$. This transfer function $G_{c p}(s)$ evaluates the 
dynamic response of the system for the current excitation load, which comprises the wind load effects as well as the effect due to tensile force (pre-stressing input) in the cables.

As in many control systems, the input excitation is of unpredictable nature and cannot be expressed deterministically by a mathematical expression (Ogata 1997). This aspect represents, from a practical point of view, the major difficulty during the design and testing of a control system, since it is not feasible to implement a control system able to perform appropriately for a general input signal. In order to achieve a rather acceptable overall performance, the constants $K_{p}, T_{i}$ and $T_{d}$ in Eq. (5) must in fact be properly adjusted. In this research project, in order to improve the performance of the controller, a tuning algorithm based on the Ziegler-Nichols stability boundary rule was implemented (Ogata 1997).

Due to the fact that the adaptive control system is placed on only one side of the glass pane its effectiveness is limited to pressure wind loadings. In order for the system to also cope with wind suctions, additional stay cables would have to be implemented on the opposite side of the glass pane.

\section{Mechanical characterization of the SMA actuators}

In order to mechanically characterize the SMA cables, in view of further $\mathrm{FE}$ and experimental assessment of the active control systems, an experimental test was carried out on small specimens. In doing so, the typical SMA wire samples consisted of straight, oxide-free NiTi martensitic actuator wires, as provided by Dynalloy, Inc.

The transformation temperature of the SMA samples was first obtained, through differential scanning calorimetry analysis (DSC), see Fig. 7a. The material mechanical properties related to temperature variations, e.g. the stress-temperature, strain-temperature and elastic modulus-temperature responses, are shown in Fig. 7b-d, respectively. Observing Fig. 7a, in particular, it is possible to notice that the activation temperatures for the tested SMA wires lie within the $40^{\circ} \mathrm{C}$ to $80^{\circ} \mathrm{C}$ range. All the other plots, Fig. $7 \mathrm{~b}-\mathrm{d}$, denote the presence of a hysteresis between heating and cooling.

\section{Dynamic response of the adaptive LG panel under a mean wind excitation}

In order to investigate the dynamic performance of the proposed adaptive control approach in reducing the displacements of the selected S2 geometry due to a mean wind pressure (according to Eurocode prescriptions (EN1991-1-4)), a numerical time-stepping method for the integration of the equation of motion was used (Santos et al. 2014). The stiffness of the system was determined using 22 degrees-of-freedom (DOF), represented in Fig. 8, which were associated to the out-ofplane displacements of the represented nodes. In order to preserve both modeling and computational time of simulations, the resulting model was implemented by taking advantage of the symmetry of the examined S2 structural assembly.

In doing so, together with the assigned mean wind pressure, the additional aerodynamic self-induced load due to the vibration of the glass panel was also taken into account. As the given system is linear, an exact solution for the equation of motion is in fact obtained, by interpolating the excitation over each time interval (Chopra 2001). The excitation function, $p(t)$, results from the combined action of the wind load, $W(t)$, and the tension in the cables, $T(t)$, for each degree of freedom.

For the time interval $t_{i} \leq t \leq t_{i+1}$, the excitation function is given by:

$p(\tau)=W(\tau)+T(\tau)=p_{i}+\frac{\Delta p_{i}}{\Delta t_{i}} \tau$

where

$\Delta p_{i}=p_{i+1}-p_{i}$.

For the general case of a damped system, the equation of motion is given by:

$m \ddot{u}+c \dot{u}+k u=p_{i}+\frac{\Delta p_{i}}{\Delta t_{i}} \tau$

The structural response in terms of displacements, $u$, is thus expressed by:

$$
\begin{aligned}
& u(\tau)=u_{i} e^{-\zeta \omega_{n} \tau}\left(\frac{\zeta}{\sqrt{1-\zeta^{2}}} \sin \omega_{D} \tau+\cos \omega_{D} \tau\right) \\
& +\dot{u}_{i} e^{-\zeta \omega_{n} \tau}\left(\frac{1}{\omega_{D}} \sin \omega_{D} \tau\right)
\end{aligned}
$$




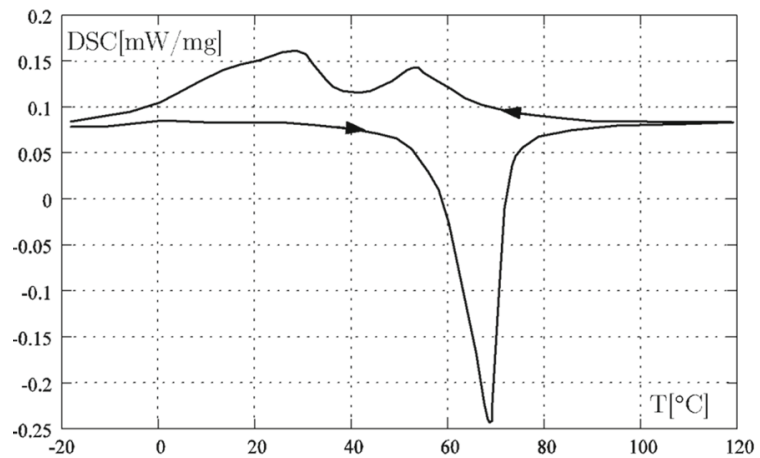

(a)

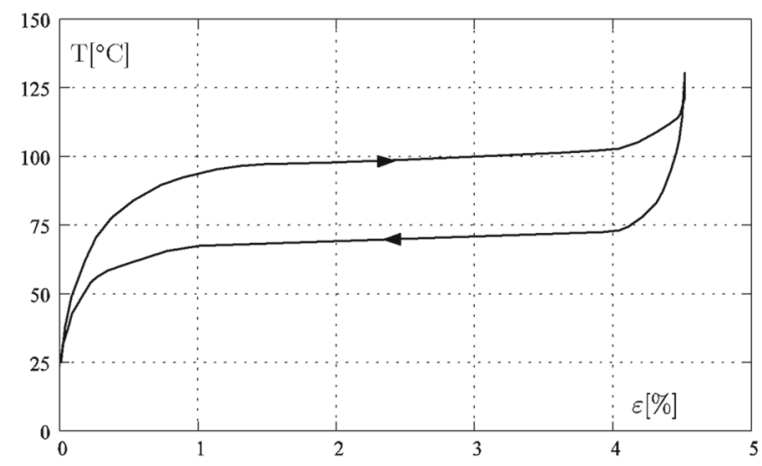

(c)

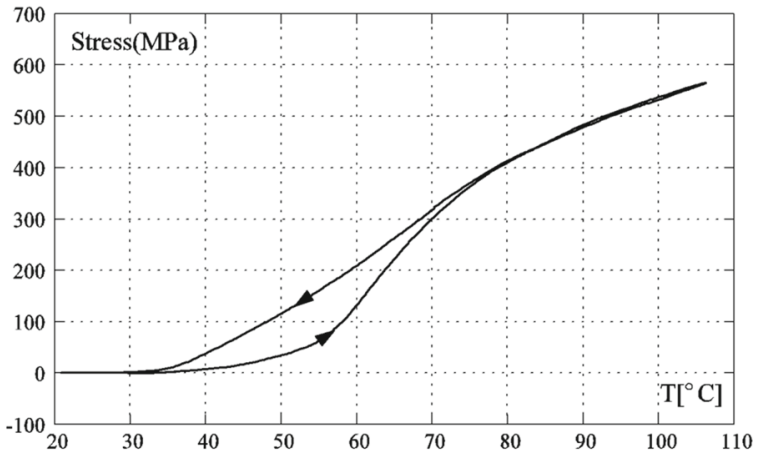

(b)

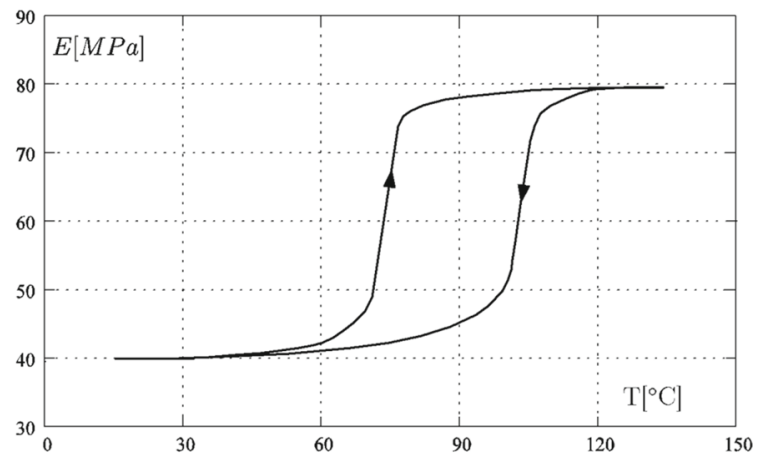

(d)

Fig. 7 Experimental mechanical characterization of the SMA components. a DSC analysis, b stress-temperature relation, $\mathbf{c}$ straintemperature relation, $\mathbf{d}$ elastic modulus-temperature relation

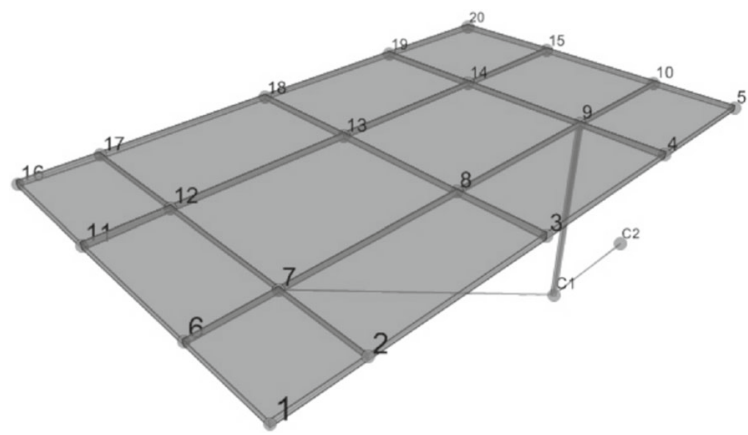

Fig. 8 Degrees of the freedom of the dynamic system, S2 configuration

$$
\begin{aligned}
& +\frac{p_{i}}{K_{n}}\left[1-e^{-\zeta \omega_{n} \tau}\left(\cos \omega_{D} \tau+\frac{\zeta}{\sqrt{1-\zeta^{2}}} \sin \omega_{D} \tau\right)\right] \\
& +\frac{\Delta p_{i}}{K_{n}}\left[\frac{\tau}{\Delta t_{i}}-\frac{2 \zeta}{\omega_{n} \Delta t_{i}}+e^{-\zeta \omega_{n} \tau}\left(\frac{2 \zeta^{2}-1}{\omega_{D} \Delta t_{i}} \sin \omega_{D} \tau\right.\right. \\
& \left.\left.+\frac{2 \zeta}{\omega_{n} \Delta t_{i}} \cos \omega_{D} \tau\right)\right]
\end{aligned}
$$

while the corresponding velocities yield:

$$
\begin{aligned}
& \dot{u}(\tau)=-u_{i} e^{-\zeta \omega_{n} \tau}\left(\frac{\omega_{n}}{\sqrt{1-\zeta^{2}}} \sin \omega_{D} \tau\right) \\
& +\dot{u}_{i} e^{-\zeta \omega_{n} \tau}\left(\cos \omega_{D} \tau-\frac{\zeta}{\sqrt{1-\zeta^{2}}} \sin \omega_{D} \tau\right) \\
& +\frac{p_{i}}{K_{n}} e^{-\zeta \omega_{n} \tau}\left(\frac{\omega_{n}}{\sqrt{1-\zeta^{2}}} \sin \omega_{D} \tau\right) \\
& +\frac{\Delta p_{i}}{K_{n} \Delta t_{i}}\left[1-e^{-\zeta \omega_{n} \tau}\left(\frac{\zeta}{\sqrt{1-\zeta^{2}}} \sin \omega_{D} \tau+\cos \omega_{D} \tau\right)\right]
\end{aligned}
$$

These equations can be rewritten as recurrence formulas, after replacing Eq. (7):

$u_{i+1}=A u_{i}+B \dot{u}_{i}+C p_{i}+D p_{i+1}$

$\dot{u}_{i+1}=A^{\prime} u_{i}+B^{\prime} \dot{u}_{i}+C^{\prime} p_{i}+D^{\prime} p_{i+1}$

In Eqs. (11)-(12), the resulting coefficients $A, B, \ldots$, $D^{\prime}$ depend on the system dynamic parameters $\omega_{n}, k, \zeta$ and on the time interval $\Delta t \equiv t_{i}$ (Chopra 2001). Given 


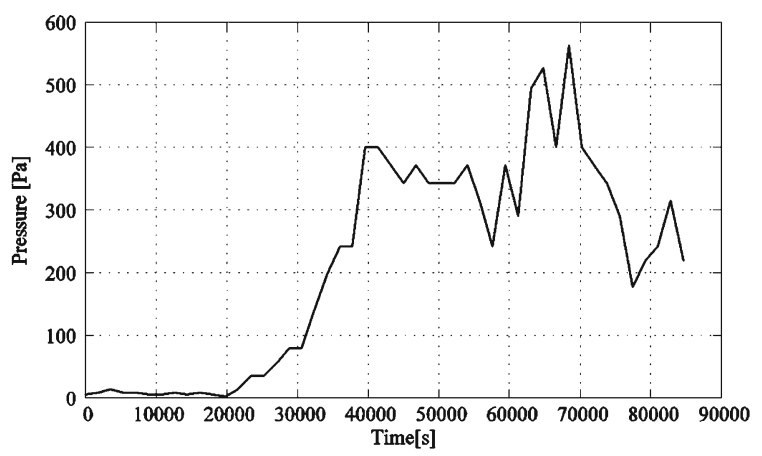

Fig. 9 Mean wind pressure time-history

that the recurrence formulas are derived from the exact solution of the equation of motion, the only restriction in terms of $\Delta t$ is that it enables a close approximation of the excitation function. The total response of the dynamic system is obtained by the superposition of the modal responses.

For this research study, the mean wind excitation series was obtained from WU Weather Underground (C) (http://www.wunderground.com/), a commercial weather service which provides real-time weather information via the Internet. The wind series was calibrated in order to yield a maximum mean wind speed of $30 \mathrm{~ms}^{-1}$ during the time frame of the analysis, which was set equal to $24 \mathrm{~h}$. The resulting timehistory, in terms of mean wind pressure, is shown in Fig. 9.

The overall performance of the proposed adaptive glass pane was then assessed under both the monolithic and layered conditions. In Fig. 10a, the response of the monolithic glazing system is proposed in terms of maximum displacements monitored at the central point of the pane, with and without active control system respectively. In Fig. 10b, the same deflection comparison is shown, but for the layered condition. From a direct comparison of Fig. 10a, b, the different performance of the same glazing assembly under the monolithic or layered conditions can be clearly noticed. In both the cases, however, the active control system is typically associated to a marked reduction of maximum deformations, hence suggesting the high efficiency of the proposed approach In Fig. 10c, finally, the time-history of maximum forces occurring in the cable restraining systems during the wind event is also proposed.
Based on the comparisons collected in Fig. 10, it is clear that under a daily mean wind pressure the implemented control system is able to fully eliminate the displacements attained at the center of the glass panes, e.g. where the maximum deformations are expected. An optimized calibration of the control system, however, should take into account a balanced combination of multiple aspects. For the same control point, for example, when moving from a monolithic to a layered situation, the amount of mean wind displacements shown by the uncontrolled systems increases from $\sim 5 \mathrm{~mm}$ ( $L / 400)$ to $\sim 13 \mathrm{~mm}(L / 140)$. With the control system off, in addition, the maximum axial forces in the cable system are mainly dependent on the assigned wind pressure, with a maximum value amounting to $\sim 3.5 \mathrm{kN}$.

In order to comply with the prescribed position setpoint, the force input due to the control system resulted equal to $10.5 \mathrm{kN}$ for the monolithic system, and increased up to $31.5 \mathrm{kN}$ for the layered configuration. The maximum temperature in the SMA wires during the same simulations were found to be $50.0^{\circ} \mathrm{C}$ and $62.5^{\circ} \mathrm{C}$, for the monolithic and layered systems respectively.

In Fig. 11, the displacements attained by the glass panes as a consequence of the wind pressure (W), the control system only (T), as well as the total response $(\mathrm{W}+\mathrm{T})$ are compared for the monolithic and layered scenarios. One can see that while the curvature induced by the control system in the glass pane is mainly associated with the short edge direction, the curvature due to wind pressure occurs in the direction of the long edge. The major effect of this finding is that from a practical point of view, it is rather difficult to control the wind displacement near the short edges of the glass pane, which remain significantly high, even with the control system activated. In any case, the rather good global performance of the adaptive control system both for the monolithic and layered situations can be clearly noticed from the same comparative plots.

In Figs. 12 and 13, for example, the maximum principal stresses occurring in glass as a consequence of the wind pressure only (W), the active control system $(\mathrm{T})$ and both of them $(\mathrm{W}+\mathrm{T})$, are also proposed. While the $\sigma_{11}$ principal stresses in glass are marginally improved by the action of the control system, the $\sigma_{22}$ stresses are almost not affected by the same control system. 


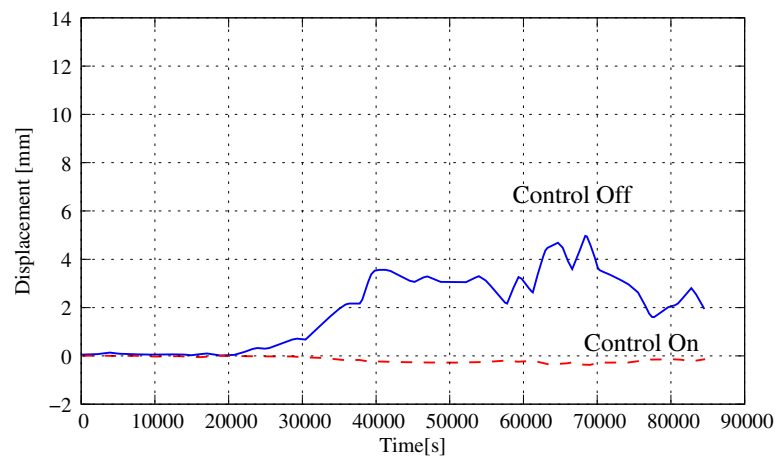

(a)

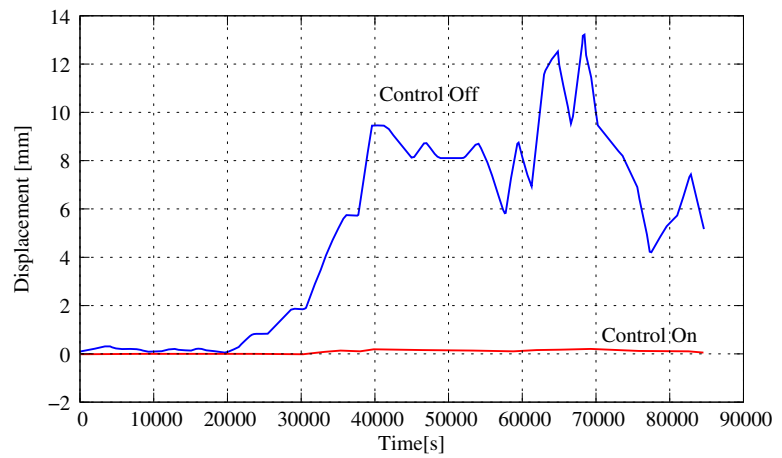

(b)

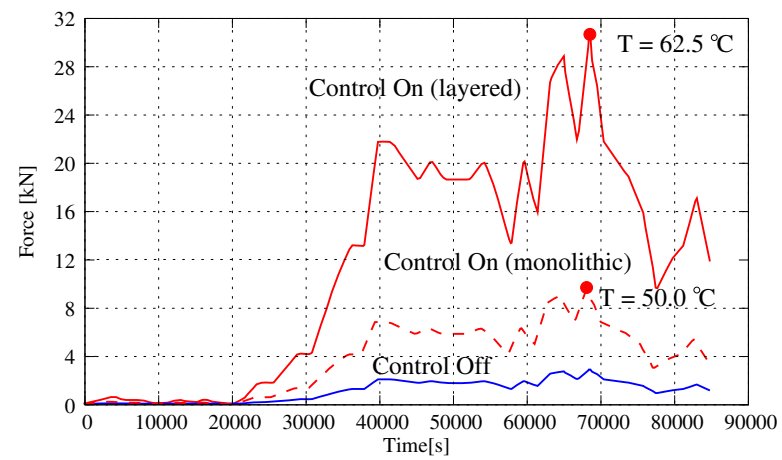

(c)

Fig. 10 Dynamic response of the S2 glass panel under a mean wind time-history pressure (see Fig. 9). a Maximum displacements with monolithic behavior, $\mathbf{b}$ maximum displacements with

\section{Experimental prototype}

Once an enhanced configuration for the cable restraining system was established (see Sect. 3), a scaled experimental prototype of an adaptive panel, serving as a proof-of-concept, was also designed and built. The prototype was inspired by the geometrical configuration of the S2 model (see Fig. 3). The wire samples, provided by Dynalloy, Inc., consisted of straight, oxide-free NiTi martensitic actuator wires with circular cross-section and $0.51 \mathrm{~mm}$ the nominal diameter. The experimental mechanical properties of these SMA wires are collected in Fig. 7. For practical purposes, during the experimental phase, an interior suction was used to deform the panel and represent a reasonable wind load, rather than an exterior pressure (see Fig. 14).

The full experimental apparatus was built up of an airtight box with dimensions $550 \times 350 \times 200 \mathrm{~mm}^{3}$, which was topped by a $500 \times 310 \mathrm{~mm}^{2}$ acrylic plate layered behavior, $\mathbf{c}$ maximum orces in the SMA cables, as a function of time

with $2.5 \mathrm{~mm}$ thickness. The acrylic plate was positioned on the top of the box, and sealed along the four edges to the box itself. Four steel struts with a diameter of $3 \mathrm{~mm}$ and a length of $93 \mathrm{~mm}$ were hen used as deviators for the SMA cable system. The test prototype was also provided with (i) a laser displacement sensor, to monitor the vertical displacement of the acrylic pane, and (ii) a pressure sensor, placed inside the box. In Fig. 15, the main features of the experimental prototype and setup are shown.

In accordance with Sect. 5, the control algorithm was based on a PID control approach, in which the displacements of the pane were reduced by defining a vertical reference position for the middle point of the acrylic pane. In this sense, the test was carried out by assuming that as the suction was imposed to the system and the acrylic pane started to deform, the so assembled prototype would have increased the stress in the restraining SMA wires, to compensate the attained deformation. 


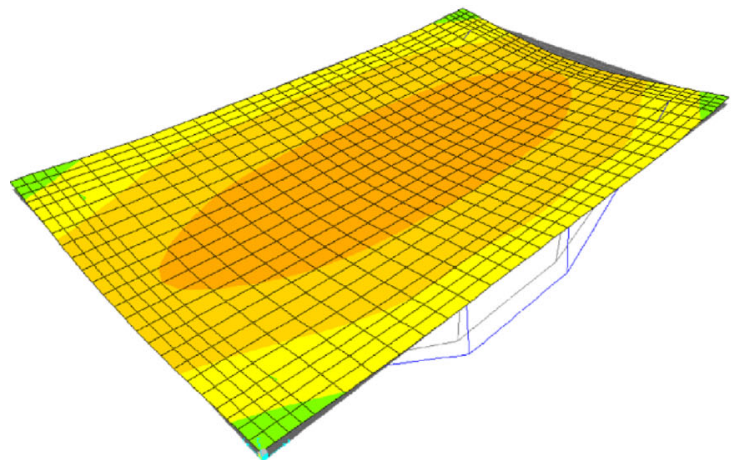

(a) $\mathrm{W}$

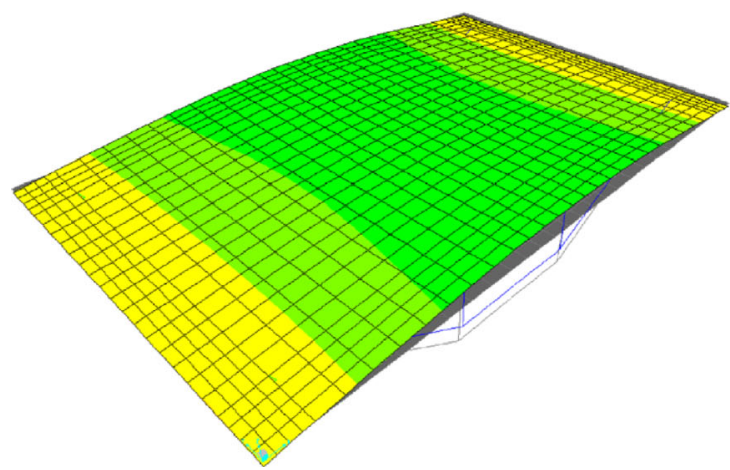

(c) $\mathrm{T}$

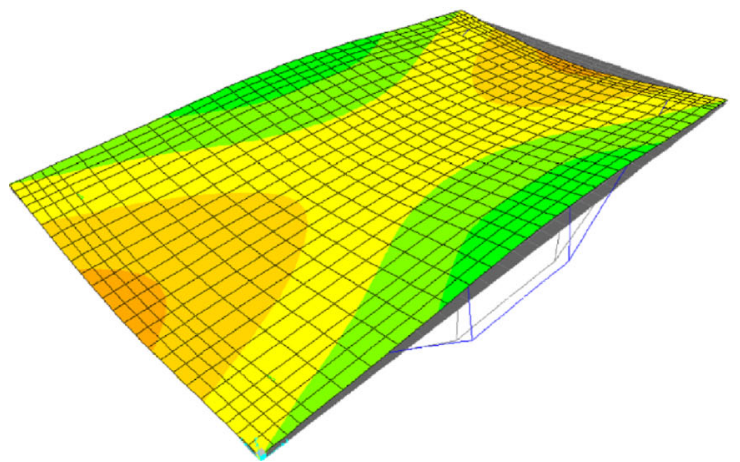

(e) $\mathrm{W}+\mathrm{T}$

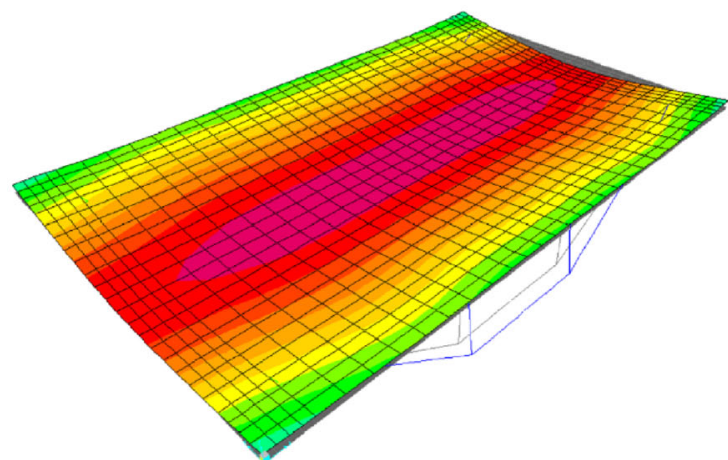

(b) $\mathrm{W}$

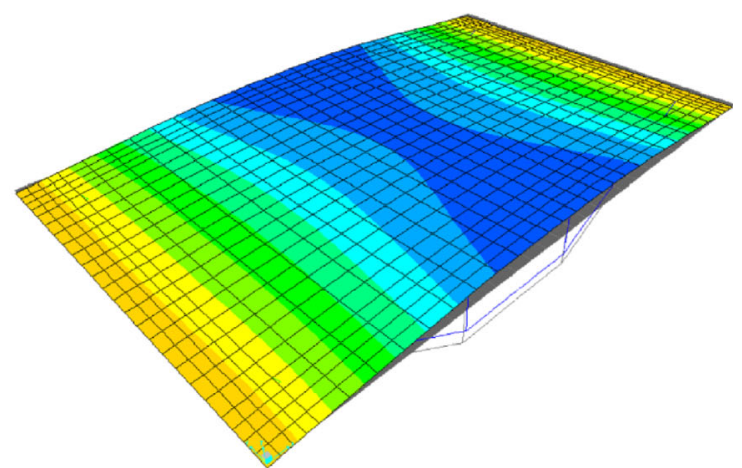

(d) $\mathrm{T}$

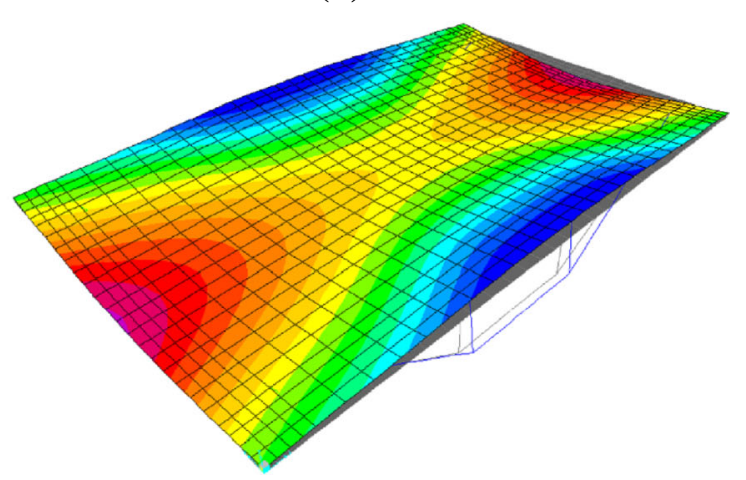

(f) $\mathrm{W}+\mathrm{T}$

-15.0-12.7-10.4-8.1-5.8-3.5 -1.2 $1.2 \quad 3.5 \quad 5.8 \quad 8.1 \quad 10.4 \quad 12.7 \quad 15.0$

Fig. 11 Maximum displacements of the active S2 glass panel $(\mathrm{mm})$ under a mean wind pressure, axonometry (SAP2000). a Wind (W), monolithic; b wind (W), layered; c control (T), monolithic; d control (T), layered; e total $(\mathrm{W}+\mathrm{T})$, monolithic; f total $(\mathrm{W}+\mathrm{T})$, layered

NiTi wire actuators. During the experimental test, the temperature attained in the NiTi wires was continuously monitored by a T-type thermocouple (CopperConstantan), with a temperature reading range comprised between $-40^{\circ} \mathrm{C}$ and $100^{\circ} \mathrm{C}$, and connected to a 


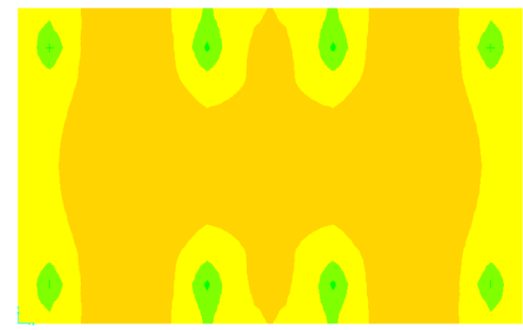

(a) $\sigma_{11}(\mathrm{~W})$

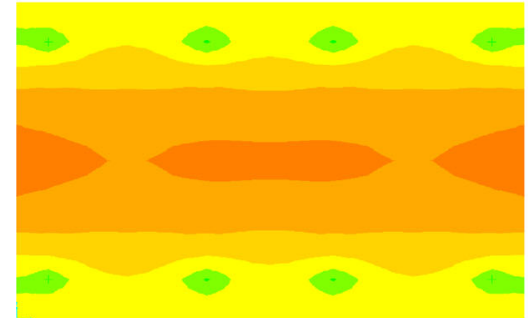

(d) $\sigma_{22}(\mathrm{~W})$

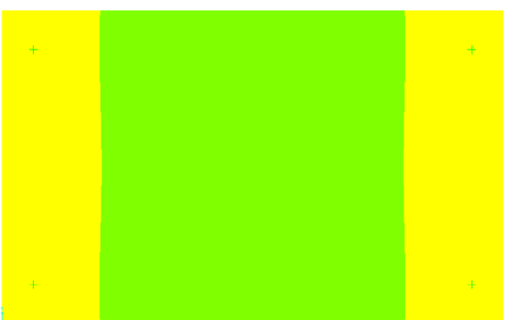

(b) $\sigma_{I l}(\mathrm{~T})$

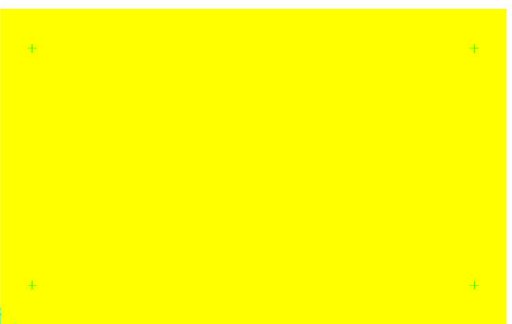

(e) $\sigma_{22}(\mathrm{~T})$

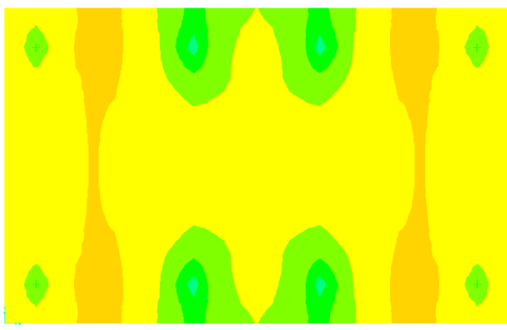

(c) $\sigma_{l 1}(\mathrm{~W}+\mathrm{T})$

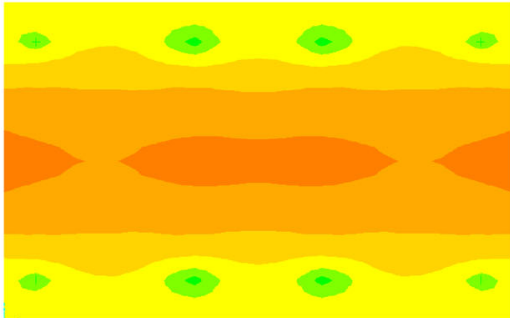

(f) $\sigma_{22}(\mathrm{~W}+\mathrm{T})$

-25.0-21.2-17.3-13.5-9.6-5.8-1.9 $1.9 \quad 5.8 \quad 9.613 .5 \quad 17.321 .2 \quad 25.0$

Fig. 12 Maximum principal stresses for the active monolithic S2 glass panel (MPa) under a mean wind pressure, top view (SAP2000). a Wind $(\mathrm{W})$; b control $(\mathrm{T})$; $\mathbf{c}$ total $(\mathrm{W}+\mathrm{T})$; d wind $(\mathrm{W})$; e control $(\mathrm{T})$; f total $(\mathrm{W}+\mathrm{T})$

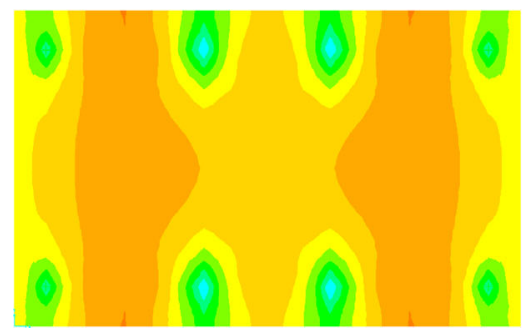

(a) $\sigma_{11}(\mathrm{~W})$

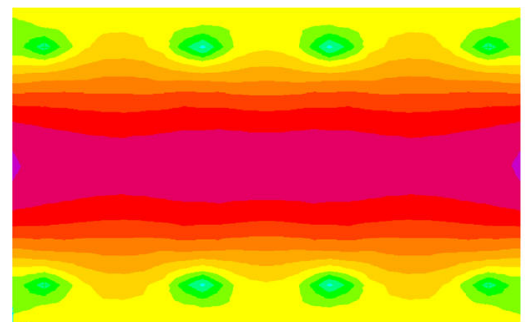

(d) $\sigma_{22}(\mathrm{~W})$

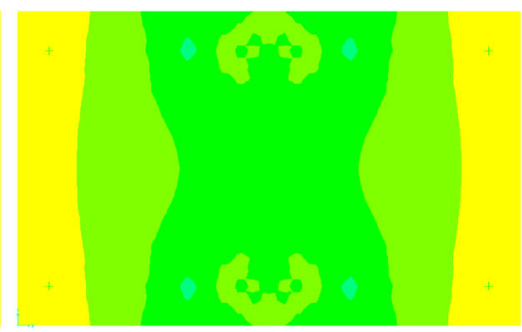

(b) $\sigma_{11}(\mathrm{~T})$

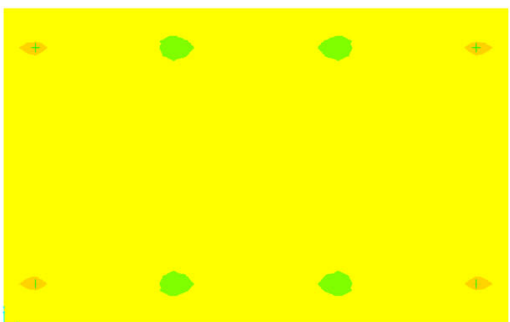

(e) $\sigma_{22}(\mathrm{~T})$

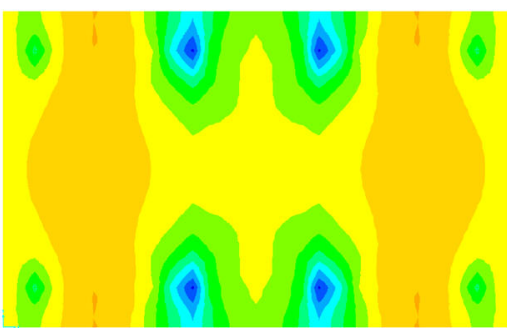

(c) $\sigma_{1 l}(\mathrm{~W}+\mathrm{T})$

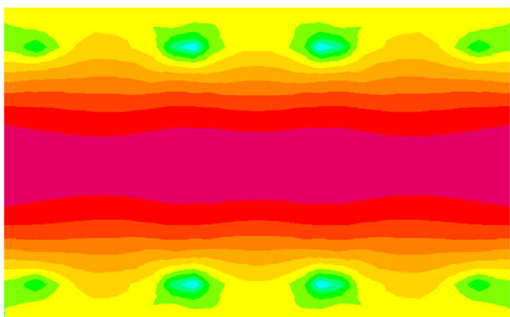

(f) $\sigma_{22}(\mathrm{~W}+\mathrm{T})$

-25.0-21.2-17.3-13.5-9.6-5.8 $-1.9 \quad 1.9 \quad 5.8 \quad 9.6 \quad 13.5 \quad 17.3 \quad 21.2 \quad 25.0$

Fig. 13 Maximum principal stresses in the active layered S2 glass panel (MPa) under a mean wind pressure, top view (SAP2000). a Wind $(\mathrm{W})$; b control $(\mathrm{T})$; $\mathbf{c}$ total $(\mathrm{W}+\mathrm{T})$; d wind $(\mathrm{W})$; e control $(\mathrm{T})$; f total $(\mathrm{W}+\mathrm{T})$ 


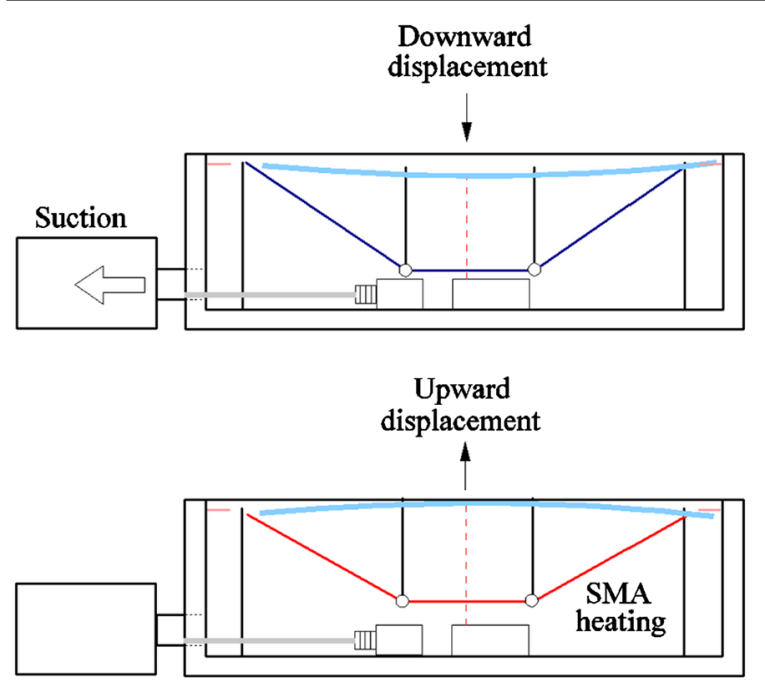

Fig. 14 Working principle of the experimental prototype (crosssection)

NI SCXI-1112 8 channel thermocouple amplifier. The control of the SMA actuators was performed in a voltage control mode, with a maximum input current of $2 \mathrm{~A}$.

A DAQ assistant express VI, using the NI-DAQmx software, was finally used to create, edit and run the analog inputs corresponding to the voltage measurement tasks. Using an averaging process, a sample compression of the data points was also performed, in order to attenuate the noise derived from the readings. In Fig. 16, two additional views of the experimental setup are shown.

The structural performance of the proposed prototype is shown in Fig. $17 \mathrm{a}-\mathrm{c}$, as obtained from the test methods and setup described above. For the given input time-history pressure (Fig. 17a), in particular, a comparison between the performance of the prototype with control system 'on' and 'off' is presented, in terms of maximum deformations at the center of the panel (Fig. 17b) and maximum temperature in the SMA wires (Fig. 17c).

In Fig. 17a, in particular, one can attest that the measured input pressures for the controlled ('Control On') and for the passive prototypes ('Control Off') are almost identical, with an initial increase to about a $-350 \mathrm{MPa}$ plateau and a subsequent decrease to zero. The response of the two prototypes in terms of displacements, however, is rather different, as it can be seen in Fig. 17b. While in the passive system the maximum displacement reaches a maximum value of about
Fig. 15 General features and instrumentation of the experimental prototype
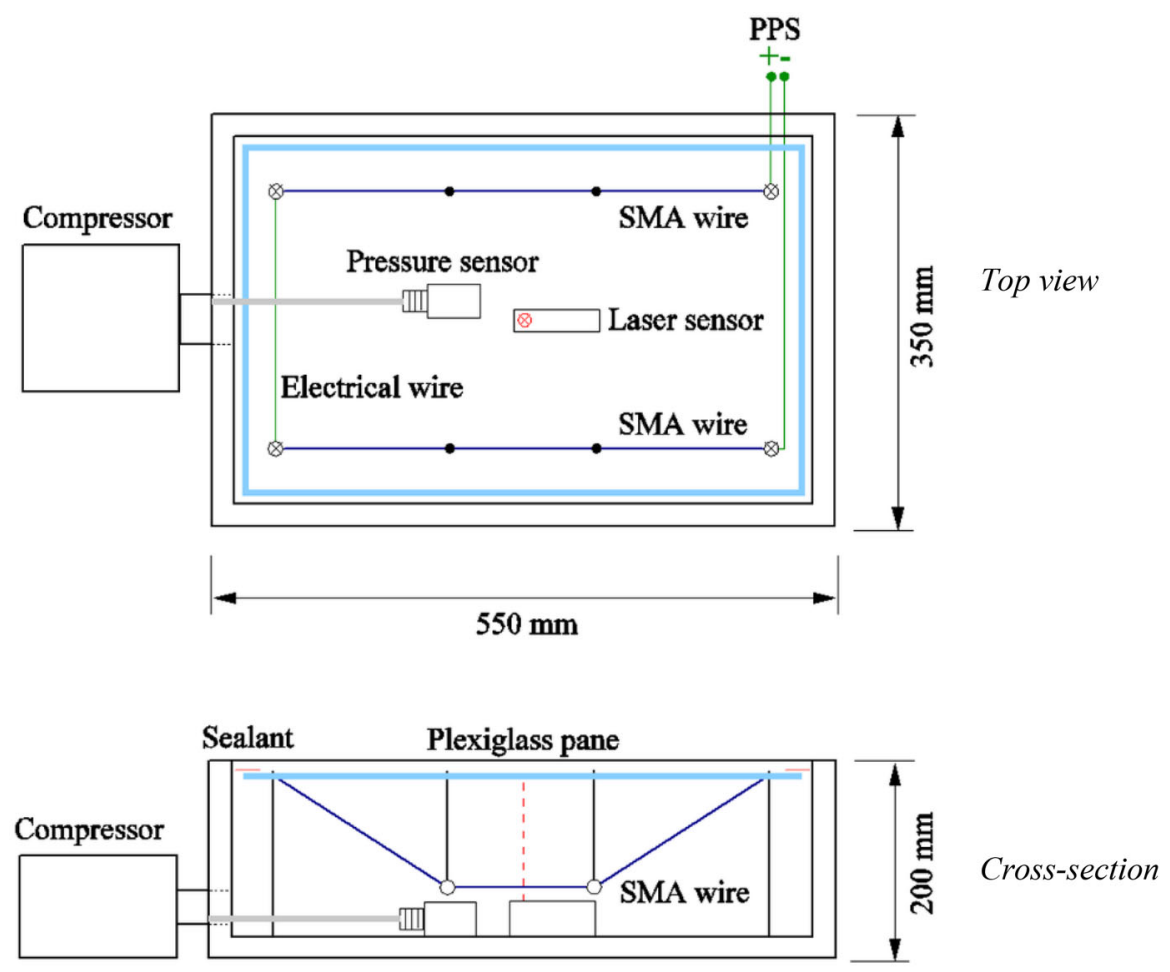


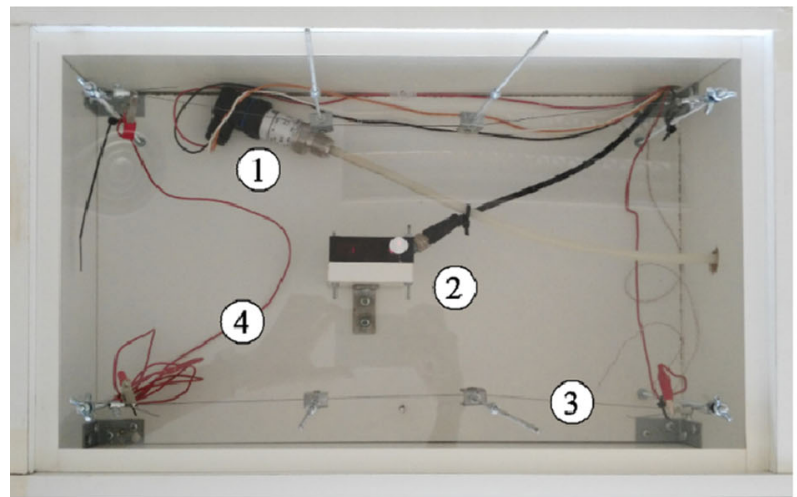

(a)

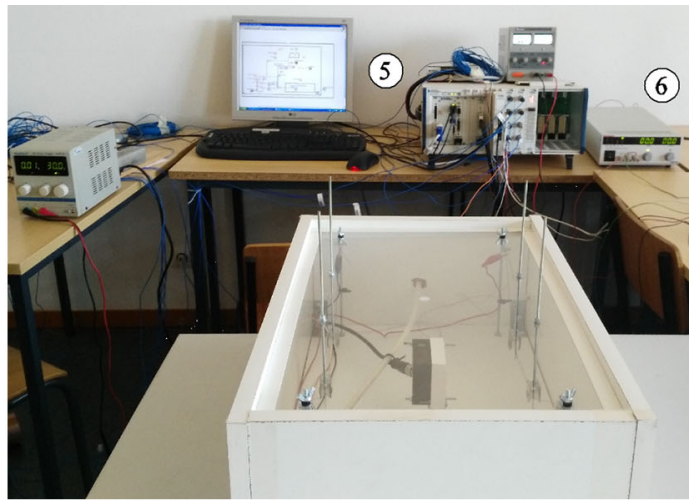

(b)

Fig. 16 Experimental setup and instrumentation. a Top view of the airtight box and $\mathbf{b}$ general view of the full system. $1-$ pressure sensor; 2-displacement sensor; 3-SMA cable; 4-electrical wire; 5-DAQ system; 6-programmable power supply

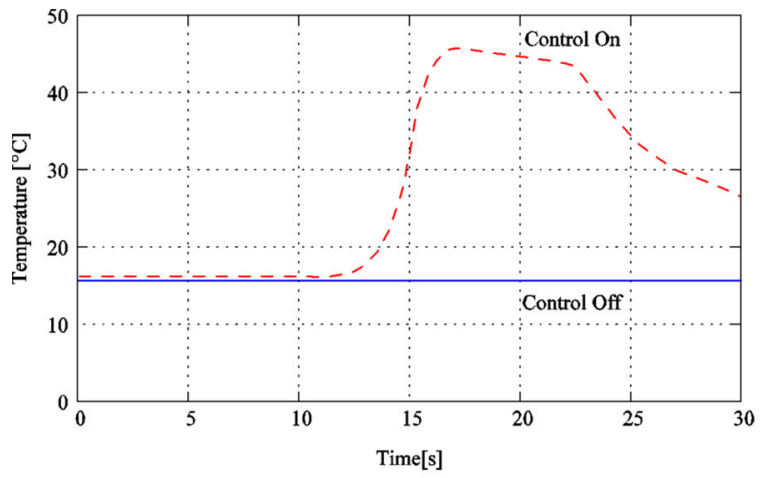

(a)

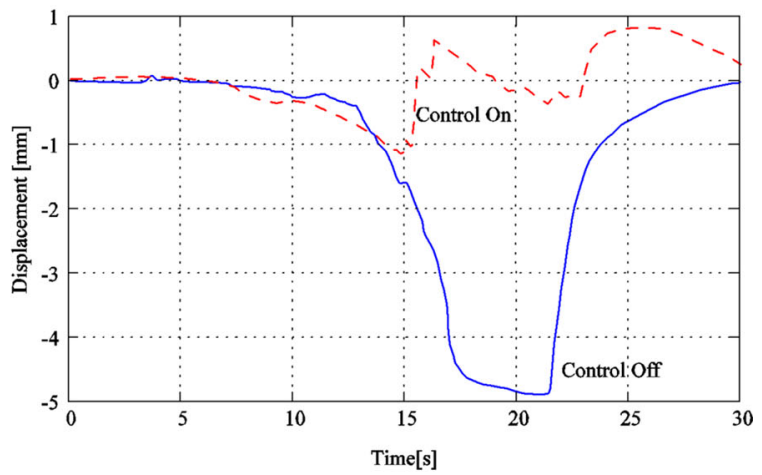

(b)

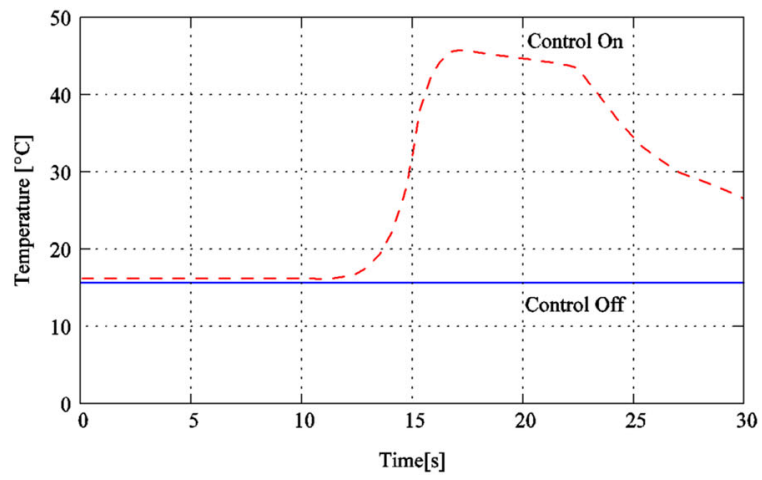

(c)

Fig. 17 Experimental results obtained for the active panel prototype, under a given pressure, with control system on and off. a Input pressure time-history, $\mathbf{b}$ displacement time-history, $\mathbf{c}$ temperature in the SMA actuators

$-5 \mathrm{~mm}$, for the system with active control the maximum deflection can rise up to a maximum of $0.8 \mathrm{~mm}$. This finding, corresponding to an overall reduction of $\sim 85 \%$ (in absolute value) the original 'passive' displacement, suggests again the high potentiality of the explored design concept. 
In Fig. 17c, finally, the time-history of maximum temperatures attained in the SMA wires is also proposed for the solutions with passive/active control. In this latter case, it can be seen that the measured temperature in the SMA wires rises to about $46^{\circ} \mathrm{C}$, during the activation phase, hence providing enhanced structural performances with overall moderate temperature variations.

Certainly, more detailed investigations are required for a fully implementation and optimization of the proposed design concept. On the other hand, the positive outcomes of this current research effort emphasize the high potentiality of active control systems for traditional glazing solutions. It is thus expected that positive contributions could be derived from the present study.

\section{Conclusions}

Although the increasing application of structural glass elements in buildings, the thermo-mechanical behavior of wide-span laminated glass panels still represents a topic that needs appropriate and specific investigations, due to the marked temperature dependence of the mechanical properties of common thermoplastic interlayers and to the general trend towards 'ultrathin' and 'ultra-light' assemblies. In them, the degree of shear connection between the glass panes and the bonding interlayer lies in fact between the monolithic limit (e.g. for low temperatures) and the layered limit (e.g. for temperatures higher than $\sim 40^{\circ} \mathrm{C}$ ). In this research project, a novel 'adaptive' design concept was explored. The influence of temperature variations on the flexibility of case study laminated glass panel was first shown, by using analytical methods and FiniteElement numerical simulations. The reference case study, representing a roof modular unit, consisted of a three-layer laminated glass panel assembled with a bracing system of external cables having a triangular shape. To improve its structural performance under variable temperatures and ordinary wind pressures, an innovative adaptive control system based on shapememory-alloy (SMA) cable actuators was proposed, with the specific aim to control and minimize the maximum deformations in glass due to mean wind pressures. In such systems, as far as the ambient and loading conditions modify, an adaptive control system continuously adjust the structural performance of the inves- tigated assembly. Static and dynamic numerical simulations were critically discussed, to assess the potentiality of the novel design concept, when applied in a roof modular unit. A small scale exploratory experimental prototype was also presented, as a proof-ofconcept. In the latter case, the geometrical configuration was derived from the parametric results provided by an optimization study, which took into consideration variations on the shape of the cable restraining system. Also in the latter case, the experimental test emphasized the feasibility and efficiency of such adaptive control approach, hence suggesting further investigations for the full optimization and development of the 'adaptive glass' concept.

Acknowledgments The cooperation of Professors F. M. Braz Fernandes and L. Gil from FCT-UNL is gratefully acknowledged. The ongoing COST Action TU1403 Adaptive facades network (2014-2018) is also acknowledged for enforcing the cooperation between the involved researchers.

\section{Compliance with ethical standards}

Conflict of interest On behalf of all authors, the corresponding author states that there is no conflict of interest.

\section{Annex}

EET terms derived from (Galuppi and Royer-Carfagni 2012) for LG plates:

- Layered flexural stiffness

$$
D_{a b s}=\sum_{i=1}^{2} D_{i}=\sum_{i=1}^{2} \frac{E h_{i}^{3}}{12\left(1-v^{2}\right)},
$$

- Monolithic flexural stiffness

$$
D_{\text {full }}=D_{a b s}+\frac{E}{\left(1-v^{2}\right)} \frac{h_{1} h_{2}}{h_{1}+h_{2}} H^{2} \text {, }
$$

- Equivalent bending stiffness

$$
I_{s}=\frac{h_{1} h_{2}}{h_{1}+h_{2}} H^{2},
$$

- $H, d_{1}$ and $d_{2}$ distances

$$
\begin{gathered}
H=h_{\text {int }}+\frac{h_{1}+h_{2}}{2}, \quad d_{1}=\frac{h_{2} H}{h_{1}+h_{2}}, \\
d_{2}=\frac{h_{1} H}{h_{1}+h_{2}}
\end{gathered}
$$


Table 2 Coefficients for 4 point-supported plates under uniformly distributed loads

\begin{tabular}{|c|c|c|c|c|c|c|c|c|c|c|}
\hline \multirow[t]{2}{*}{$\mathrm{a}(\mathrm{mm})$} & \multicolumn{10}{|l|}{$\lambda=\mathrm{b} / \mathrm{a}$} \\
\hline & 0.1 & 0.2 & 0.3 & 0.4 & 0.5 & 0.6 & 0.7 & 0.8 & 0.9 & 1 \\
\hline 500 & 30.288 & 30.45 & 31.083 & 32.392 & 34.686 & 38.147 & 42.534 & 46.630 & 48.187 & 45.601 \\
\hline 600 & 21.033 & 21.13 & 21.585 & 22.495 & 24.088 & 26.491 & 29.538 & 32.382 & 33.463 & 31.667 \\
\hline 800 & 11.831 & 11.94 & 12.142 & 12.653 & 13.549 & 14.901 & 16.615 & 18.215 & 18.823 & 17.813 \\
\hline 1000 & 7.572 & 7.619 & 7.771 & 8.098 & 8.672 & 9.537 & 10.633 & 11.658 & 12.047 & 11.400 \\
\hline 1500 & 3.365 & 3.386 & 3.454 & 3.599 & 3.854 & 4.239 & 4.726 & 5.181 & 5.354 & 5.067 \\
\hline 2000 & 1.893 & 1.905 & 1.943 & 2.025 & 2.168 & 2.384 & 2.658 & 2.914 & 3.012 & 2.850 \\
\hline 2500 & 1.212 & 1.219 & 1.243 & 1.296 & 1.387 & 1.526 & 1.701 & 1.865 & 1.927 & 1.824 \\
\hline 3000 & 0.841 & 0.847 & 0.863 & 0.900 & 0.964 & 1.060 & 1.182 & 1.295 & 1.339 & 1.267 \\
\hline 3500 & 0.618 & 0.622 & 0.634 & 0.661 & 0.708 & 0.779 & 0.868 & 0.952 & 0.983 & 0.931 \\
\hline 4000 & 0.473 & 0.476 & 0.486 & 0.506 & 0.542 & 0.596 & 0.665 & 0.729 & 0.753 & 0.713 \\
\hline 4500 & 0.374 & 0.376 & 0.384 & 0.400 & 0.428 & 0.471 & 0.525 & 0.576 & 0.595 & 0.563 \\
\hline 5000 & 0.303 & 0.305 & 0.311 & 0.324 & 0.347 & 0.381 & 0.425 & 0.466 & 0.482 & 0.456 \\
\hline 5500 & 0.250 & 0.252 & 0.257 & 0.268 & 0.287 & 0.315 & 0.352 & 0.385 & 0.398 & 0.377 \\
\hline 6000 & 0.210 & 0.212 & 0.216 & 0.225 & 0.241 & 0.265 & 0.295 & 0.324 & 0.335 & 0.317 \\
\hline
\end{tabular}

The provided values for the $\psi$ coefficient $\left(\mathrm{mm}^{-2}\right)$ must be multiplied by a factor $10^{-6}$

- $\psi$ coefficients for 4 point-supported plates under uniformly distributed loads, with $a, b$ the maximum and minimum sizes respectively, while $\lambda=$ $b / a$ denotes the aspect ratio (in evidence, the range of values of interest for the current research study, with $\lambda=0.625$ and $a=3200 \mathrm{~mm}$ ):

\section{References}

Batinger, M., Feldmann, M.: Design concept for bolted glass. In: Bos, Louter, Veer (eds.) Proceedings of Challenging Glass 2 - Conference on Architectural and Structural Applications of Glass (2010)

Bedon, C., Amadio, C.: Exploratory finite-element investigation and assessment of standardized design buckling criteria for two-sided linear adhesively supported glass panels under in-plane shear loads. Eng. Struct. 106(1), 273-287 (2016). doi:10.1016/j.engstruct.2015.10.033

Bedon, C., Louter, C.: Exploratory numerical analysis of SGlaminated reinforced glass beam experiments. Eng. Struct. 75, 457-468 (2014). doi:10.1016/j.engstruct.2014.06.022

Bennison, S.J., Quin, M.H., Davies, P.: High-performance laminated glass for structurally efficient glazing. In: Innovative Light-Weight Structures and Sustainable Facades, Hong Kong (2008)

Blyberg, L., Serrano, E., Enquist, B., Starley, M.: Adhesive joints for structural timber/glass applications: experimental testing and evaluation methods. Int. J. Adhes. Adhes. 35, 76-87 (2012). doi:10.1016/j.ijadhadh.2012.02.008

Bos, F., Veer, F.: Transparent polymer joints in glass structures. In: Proceedings of Glass Performance Days, pp. 1-6 (2007)
Callewaert, D., Belis, J., Delince, D., Van Impe, R.: Experimental stiffness characterization of glass/ionomer laminates for structural applications. Constr. Build. Mater. 37, 685-692 (2012). doi:10.1016/j.conbuildmat.2012.07.035

Chopra, A.K.: Dynamics of Structures: Theory and Applications to Earthquake Engineering, 2nd edn. Prentice-Hall, Inc., Upper Saddle River (2001)

Cismasiu, C., Santos, F.P.A.: Numerical simulation of superelastic shape memory alloys subjected to dynamic loads. Smart Mater. Struct. 17(2), 25-36 (2008). doi:10.1088/ 0964-1726/17/2/025036

CNR DT210/2013: Istruzioni per la Progettazione, l'Esecuzione ed il Controllo di Costruzioni con Elementi Strutturali di Vetro

Computers and Structures Inc.: SAP2000 v.18 - Integrated Finite Element Analysis and Design of Structures. Computers and Structures Inc., Berkeley (2015)

Cupac, J., Louter, C.: Post-tensioned structural glass beamscomparative experimental study. In: Proceedings of Advanced Building Skins, Graz, 23-24 April 2015 (2015)

Dispersyn, J., Belis, J., Sonck, D.: New glass design method for adhesive point-fixing applications. Proc. Inst. Civil Eng. Struct. Build. 168(7), 479-489 (2015). doi:10.1680/stbu.13. 00103

Duerig, T.W., Pelton, A.R.: Materials Properties Handbook: Titanium Alloys. ASM International, Almere (1994)

EN 572-2: 2004: Glass in Buildings—Basic Soda Lime Silicate Glass Products. CEN, Brussels, Belgium (2004)

EN1991-1-4: Eurocode 1: actions in structures-part 1-4: general actions-wind actions, CEN, Brussels, Belgium

Froli, M., Lani, L.: Analisi strutturale di grandi lastre in vetro stratificato rinforzate con cavi in acciaio. Costruzioni Metalliche (2) (2007) 
Galuppi, L., Royer-Carfagni, G.: The effective thickness of laminated glass plates. J. Mech. Mater. Struct. 7(4), 375-400 (2012). doi:10.2140/jomms.2012.7.375

Huang, W.: On the selection of shape memory alloys for actuators. Mater. Des. 23(1), 11-19 (2002). doi:10.1016/ S0261-3069(01)00039-5

Jordão, S., Pinho, M., Costa Neves, L., Martins, J.P., Santiago, A.: Behaviour of laminated glass beams reinforced with prestressed cables. Steel Constr. 7(3), 1-4 (2014). doi:10.1002/ stco.201410027

Kamerling, W.: Design of cable strengthened beams for glass structures. In: Bos, Louter, Nijsse, Veer (eds.) Proceedings of Challenging Glass 3-Conference on Architectural and Structural Applications of Glass, pp. 455-466 (2012). doi:10.3233/978-1-61499-061-1-455

Louter, C., Cupac, J., Lebet, J.P.: Exploratory experimental investigations on post-tensioned structural glass beams. J. Facade Des. Eng. 2(1-2), 3-18 (2014). doi:10.3233/FDE-130012

Martens, K., Caspeele, R., Belis, J.: Development of composite glass beams: a review. Eng. Struct. 101, 1-15 (2015). doi:10. 1016/j.engstruct.2015.07.006

Meyers, G.: Blast-resistant glazing. Military Eng. 78(509), 473474 (1986)

Neto, P., Alfaiate, J., Valarinho, L., Correia, J.R., Branco, F.A., Vinagre, J.: Glass beams reinforced with GFRP laminates: experimental tests and numerical modelling using a discrete strong discontinuity approach. Eng. Struct. 99, 253263 (2015). doi:10.1016/j.engstruct.2015.04.002

Ogata, K.: Modern Control Engineering, 3rd edn. Prentice-Hall International Inc, Upper Saddle River (1997)

Overend, M., Nhamoinesu, S., Watson, J.: Structural performance of bolted connections and adhesively bonded joints in glass structures. J. Struct. Eng. 12(139), 04013015 (2013). doi:10.1061/(ASCE)ST.1943-541X.0000748

Petterson, M.: Structural Glass Facades and Enclosures. Wiley, Hoboken (2011)

Santos, F.A., Cismasiu, C., Bedon, C.: Smart glazed cable façade subjected to a blast loading. Proc. Inst. Civil Eng. Struct. Build. 169(3), 223-232 (2016). doi:10.1680/jstbu.14.00057

Santos, F.A., Goncalves, P.F., Cismasiu, C., Gamboa-Marrufo, M.: Smart glass facade subjected to wind loadings. Proc. Inst. Civil Eng. Struct. Build. 167(12), 743-752 (2014). doi:10.1680/stbu. 13.00011

Santos, F.A., Rodrigues, A., Micheletti, A.: Design and experimental testing of an adaptive shape-morphing tensegrity structure, with frequency self-tuning capabilities, using shape-memory alloys. Smart Mater. Struct. 24(10), 105008 (2015). doi:10.1088/0964-1726/24/10/105008

Shitanoki, Y., Bennison, S.J.: Thin glass/ionomer (TGIO) laminates for high performance light weight glazing. In: Proceedings of GlassCon Global Conference-Innovation in Glass Technology (PA, USA), pp. 620-631 (2014)

Van Duser, A., Jagota, A., Bennison, S.J.: Analysis of glass/polyvinyl butyral laminates subjected to uniform pressure. J. Eng. Mech. 125(4), 435-438 (1999). doi:10.1061/ (ASCE)0733-9399(1999)125:4(435)

Wölfel, O.: Nachgiebiger verbund eine nherungslsung und deren anwendungsmglichkeiten. Stahlbau 6, 173-180 (1987)

WU Weather Underground $\odot$, http://www.wunderground.com/. The Weather Channel Interactive, Inc., Atlanta (GA, USA) (2015) 